\title{
Review \\ Transposable Elements and Human Diseases: Mechanisms and Implication in the Response to Environmental Pollutants
}

\author{
Benoît Chénais
}

check for updates

Citation: Chénais, B. Transposable Elements and Human Diseases: Mechanisms and Implication in the Response to Environmental

Pollutants. Int. J. Mol. Sci. 2022, 23, 2551. https://doi.org/10.3390/ijms 23052551

Academic Editor: Agustin F. Fernandez

Received: 24 January 2022

Accepted: 22 February 2022

Published: 25 February 2022

Publisher's Note: MDPI stays neutral with regard to jurisdictional claims in published maps and institutional affiliations.

Copyright: (C) 2022 by the author. Licensee MDPI, Basel, Switzerland. This article is an open access article distributed under the terms and conditions of the Creative Commons Attribution (CC BY) license (https:// creativecommons.org/licenses/by/ $4.0 /)$.
BiOSSE (Biology of Organisms: Stress, Health, Environment), UFR Sciences et Techniques, Le Mans University, F-72085 Le Mans, France; bchenais@univ-lemans.fr

\begin{abstract}
Transposable elements (TEs) are recognized as major players in genome plasticity and evolution. The high abundance of TEs in the human genome, especially the Alu and Long Interspersed Nuclear Element-1 (LINE-1) repeats, makes them responsible for the molecular origin of several diseases. This involves several molecular mechanisms that are presented in this review: insertional mutation, DNA recombination and chromosomal rearrangements, modification of gene expression, as well as alteration of epigenetic regulations. This literature review also presents some of the more recent and/or more classical examples of human diseases in which TEs are involved. Whether through insertion of LINE-1 or Alu elements that cause chromosomal rearrangements, or through epigenetic modifications, TEs are widely implicated in the origin of human cancers. Many other human diseases can have a molecular origin in TE-mediated chromosomal recombination or alteration of gene structure and/or expression. These diseases are very diverse and include hemoglobinopathies, metabolic and neurological diseases, and common diseases. Moreover, TEs can also have an impact on aging. Finally, the exposure of individuals to stresses and environmental contaminants seems to have a non-negligible impact on the epigenetic derepression and mobility of TEs, which can lead to the development of diseases. Thus, improving our knowledge of TEs may lead to new potential diagnostic markers of diseases.
\end{abstract}

Keywords: transposable element; cancer; metabolic disease; neurologic disease; aging; common disease; environmental pollutants; epigenetics; DNA methylation; DNA repair

\section{Transposable Elements of the Human Genome}

Like many other eukaryotic genomes, the human genome is littered with ancestral traces of transposable element (TE) invasion. These TEs and TE fragments now represent nearly half of the genome [1,2]. Most of these TE insertions have lost their ability to propagate in the genome, but all of these TEs remain a source of chromosome recombination and mutations. As described elsewhere, TEs are diverse in nature and two main classes are identified based on their mechanism of transposition [3]. Class I elements, retroelements or retrotransposons, propagate by reverse transcription of an RNA intermediate. Class II elements, or DNA transposons, move primarily by a "cut-and-paste" mechanism involving excision and reinsertion of their DNA sequence. In addition, a large number of nonautonomous repeat sequences are affiliated with TEs but are dependent on the enzyme(s) encoded by an auxiliary element, which is itself an autonomous TE, to ensure their mobility and amplification in the genome. Short Interspersed Nuclear Elements (SINEs) elements are the major class of these non-autonomous TEs that have widely invaded the human genome [2].

Class I elements are by far the most numerous in the human genome. They are subdivided into retrotransposons with long terminal repeats (LTRs) and retrotransposons without LTRs. The latter are very predominant, and 75.2\% of human TEs are LTR-less retrotransposons, representing alone at least 33.6\% of the whole human genome [1] (Figure 1). 
Among these LTR-less retrotransposons, the Long INterspersed Nuclear Element-1 (LINE1 or L1; Figure 2a) has undergone an exceptional expansion and now counts about 500,000 copies, mostly fragmented. This accounts for $38 \%$ of human TEs and $16.9 \%$ of the entire genome (Figure 1). However, only a very small fraction of these LINE-1s is active, i.e., capable of transposition, which means being able to propagate through the reverse transcription of an RNA intermediate and insertion of this DNA at another location in the genome. Thus, about 100 sequences among the L1PA1, L1PA2 subfamilies or Homo sapiens-specific LINE-1s (L1Hs) are active [4].

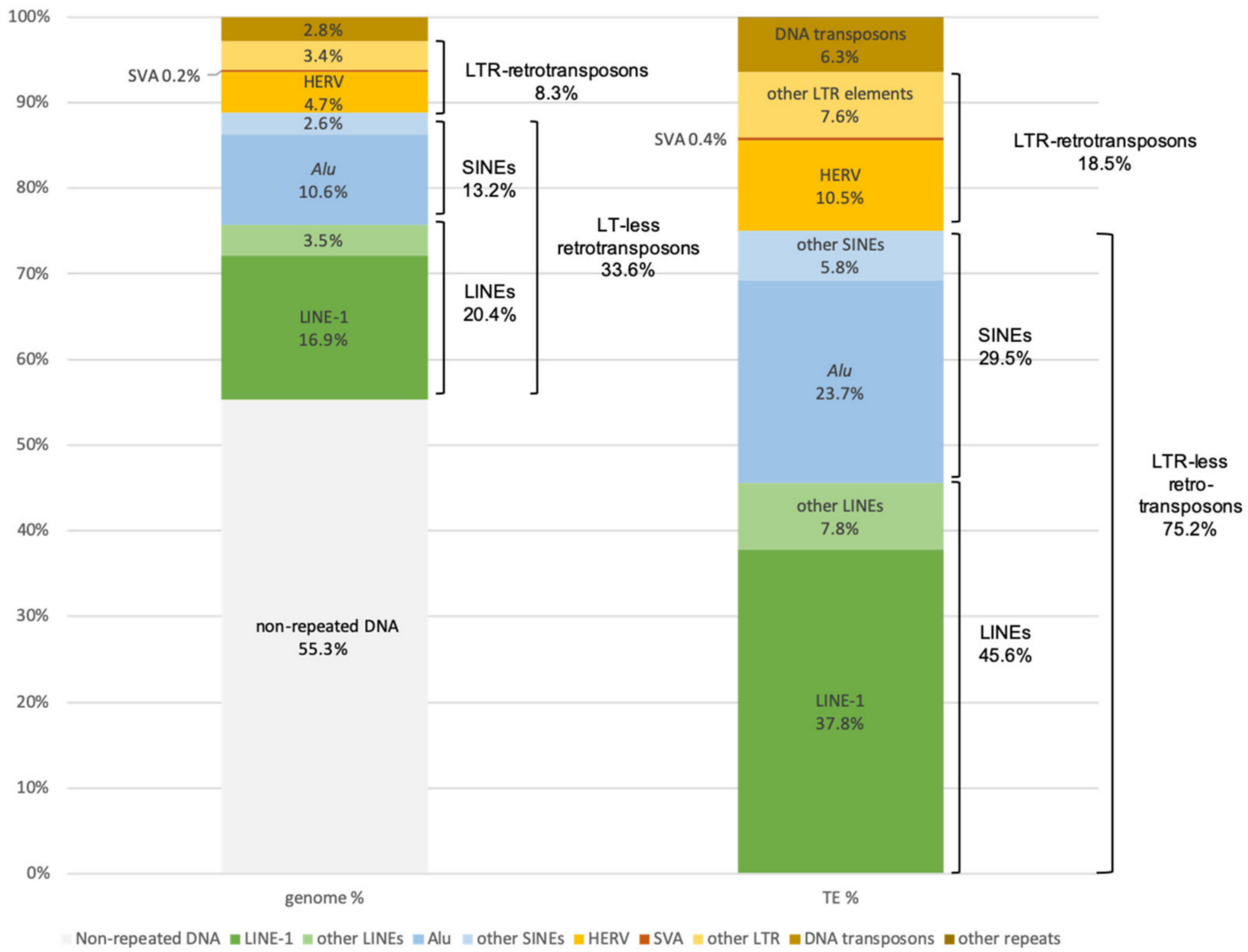

Figure 1. Proportions of transposable elements (TEs) in the human genome and their distribution in different families and subfamilies. Left panel: the percentage of each class or subclass of TEs is indicated with respect to the whole genome according to data from [1]. Right panel: the distribution of TEs in each category is given as a percentage of the total TEs present in the genome according to [1].

The second most frequent category of TEs is the non-autonomous SINEs, in particular the Alu repeats (Figure 2b), which correspond to $24 \%$ of TEs and $10.6 \%$ of the genome (Figure 1). These $A l u$ repeats are present in nearly one million copies in the entire human reference genome [1] and are derived from a few young Alu subfamilies $(A l u \mathrm{Y})$, traces of an explosion of $A l u$ retrotransposition in ancestral primates dating back 35 to 40 million years [5]. The Alu sequences are dependent on the endonuclease and reverse transcriptase activities of the LINE-1 element for propagation in genomes. Other SINEs found in humans are the Mammalian-wide Interspersed Repeat (MIR) elements and, in particular, MIR3. Other non-autonomous elements composed of a composite assembly of sequences homologous to SINEs, Variable Number of Tandem Repeats (VNTR) and Alu sequences, hence their name SVA (for SINE, VNTR, Alu; Figure 2c), are mobilizable, i.e., can be moved by the enzymes of LINE-1 elements. There are a limited number of subfamilies of $A l u$ and SVA elements capable of mobilization in present-day humans: for example, Alu Ya5, AluYb8, $A l u \mathrm{Yb} 9$, SVA-E and SVA-F. The LINE-1 elements are active in the germline making LINE-1, Alu and SVA integrations common and segregating DNA markers in populations [4,6,7]. 
(a)

LINE-1 ( 6 kb)

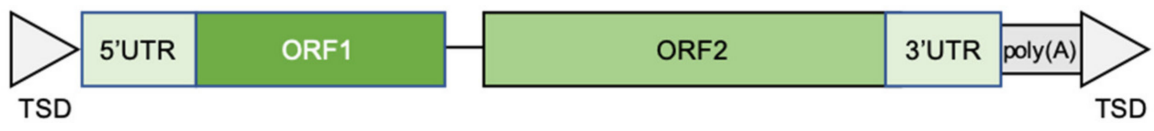

(b)

$A l u(\sim 300 \mathrm{pb})$

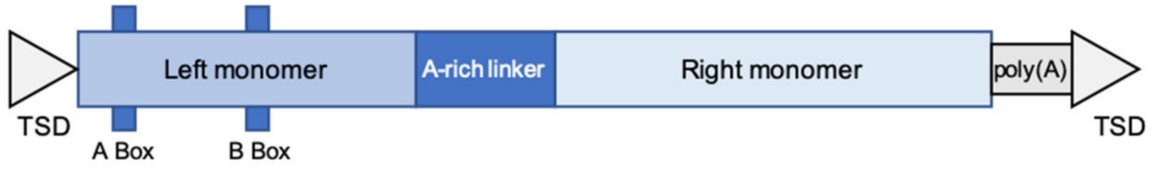

(c)

$\operatorname{SVA}(\sim 2-3 \mathrm{~kb})$

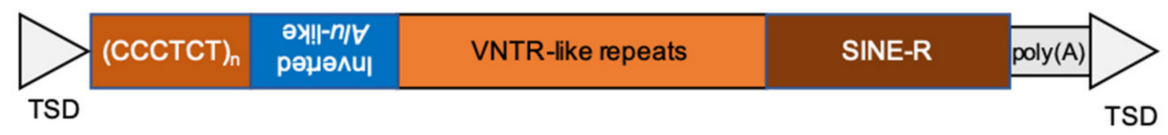

(d)

HERV ( 10 kb)

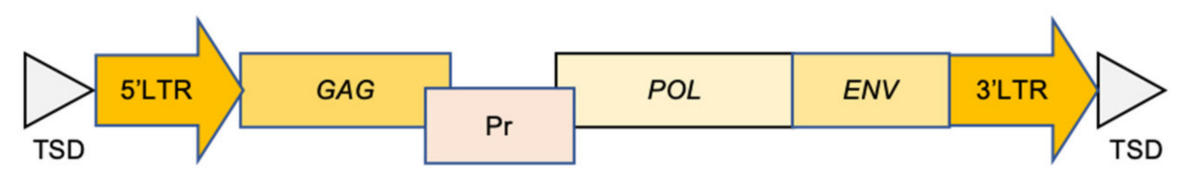

Figure 2. Schematic structure of the main human TEs of class I (retroelements). (a) The long terminal repeats (LTR)-less retrotransposon LINE- 1 is commonly constituted of two open reading frames (ORF-1 and -2) with untranslated regions (UTR) on both sides and a $3^{\prime}$ end poly(A) tail. The sequence is flanked by target duplication sites (TSD). (b) The non-autonomous LTR-less retroelement Alu usually harbors two monomers separated by a A-rich linker. Alu also displays a poly(A) tail and TSDs. (c) SVA elements are non-autonomous composite TEs classically constituted of a C-rich repeat, inverted Alu-like sequence, VNTR-like repeats and SINE sequence. (d) The classical structure of the main human LTR-retrotransposons HERVs includes TSDs, $5^{\prime}$ and $3^{\prime}$ LTR, the three retroviral ORFs (GAG, POL, ENV) and an additional ORF (Pr).

The LTR retrotransposons are present in smaller numbers in the human genome and are mainly represented by Human Endogenous RetroVirus (HERVs; Figure 2d), which resemble retroviruses in both structure and mechanism of mobility but lack functional envelope genes. In humans, the activity of LTR retrotransposons has been nearly extinguished over the last few million years [8], although their sequences still represent about $8 \%$ of our genome (Figure 1). The various HERVs are named according to the transfer RNA that initiates their reverse transcription reaction; the most recent active subfamily is HERV-K (initiated by the lysine transfer RNA). There are also HERV-I (initiated by isoleucine tRNA) and HERV-L (initiated by leucine tRNA) sequences. The current human genome still has insertion polymorphisms for these HERV elements. LTRs flanking full proviral insertions tend to recombine, removing intervening sequences and reducing the insertion to a solo LTR [9].

Class II elements, or transposons, are much less numerous in the human genome, accounting for only $6 \%$ of TEs and $2.8 \%$ of the entire genome (Figure 1). They mainly belong to the following three superfamilies: (i) TC-1/mariner, i.e., mariner, MER2-Tigger, and Tc2; (ii) hAT, i.e., MER-1-Charlie and Zaphod; and (iii) PiggyBac [1].

TEs are an evolutionary force that contributes to the genetic diversity of organisms, especially when they are recruited to the host genome to become new genes; this domestication of TEs is a source of genetic innovation [10,11]. However, transposition activity can also contribute to the emergence of human diseases and the insertion of a TE into the genome has several direct or indirect consequences on the structure of the genome and the control of gene expression. 


\section{TE Insertion and Its Consequences on the Genome and Gene Expression}

Regarding events that can lead to disease in humans, three major groups of mechanisms can be distinguished: (1) genomic rearrangements due to TE abundance; (2) modification of gene structure and regulatory regions by TE insertion, and (3) alteration of epigenetic controls $[4,12,13]$.

\subsection{Chromosome Rearrangements}

The high abundance of LINE- 1 and Alu repeats (approximately $17 \%$ and $11 \%$ of the human genome, respectively) favors ectopic recombination, i.e., recombination between non-homologous loci. Such recombination often results in significant chromosomal rearrangements such as gene deletions, duplications, translocations or chromosomal inversions that are the source of pathologies (as described in the above paragraphs 3 and 4). An example of this type of recombination between two non-allelic insertions is given in Figure 3. In this case, Alu-Alu recombination occurred between tandem AluYa5 insertions at the ubiquitin E2 T conjugating enzyme (UBE2T) gene causing Fanconi anemia. The rearrangement causes an interstitial deletion encompassing exons $2-6$ of the paternal allele, with a corresponding duplication of the maternal allele in the patient [14].

(a)

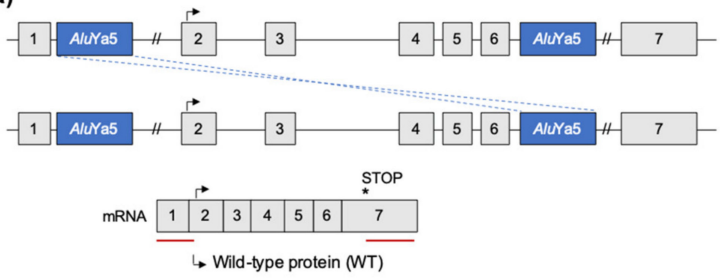

(b)

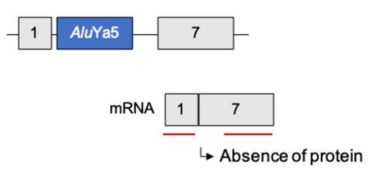

(c)

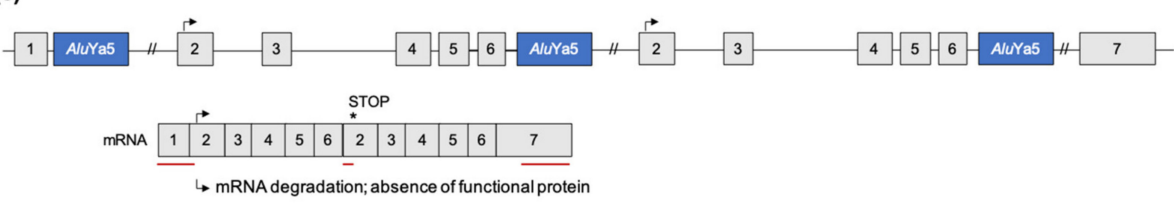

Figure 3. Insertion of $A l u$ elements and recombination. Example of recombination between two Alu Ya5 insertions in the parental alleles of the UBE2T gene (a), leading to one recombination allele with deletion (b) and one recombination allele with duplication (c). The exons are represented by grey boxes and the AluYa5 insertions by blue boxes. Figure adapted from [14].

Indeed, LINE-1 and Alu elements are frequently observed in or near breakpoints of chromosomal rearrangements, and LINE-1 alone accounts for 19\% of the 2081 breakpoints analyzed in a dataset of 17 entire human genomes [15]. Although present in smaller numbers in the human genome, DNA transposons can also be a source of chromosomal rearrangement. For example, the MER20 transposon is found on chromosome 19 and appears to be most notably linked to the development of acute lymphoblastic leukemia among the 10 different leukemias or lymphomas studied [16].

\subsection{Modification of the Structure and Expression of Genes by the Insertion of ETs}

Another way for TEs to have an impact on the human genome and to induce diseases is to modify the structure of genes and their regulatory regions. Indeed, de novo insertion, i.e., acquired directly in the patient or a mosaic parent, or an insertion inherited from the ascendants as a classical allele (i.e., insertion allele) can be responsible for diseases that 
behave like classical monogenic diseases. For this to happen, the TE insertion must appear in the germline and critically affect the function of the gene. The TE insertion will therefore create a new allele, which can be either a loss of function allele or a gain of function allele.

The insertion of a TE into a gene can have several consequences, including the creation of new exons or new introns, which are called exonization and intronization, respectively. The creation of a new exon causes a reading frame shift and/or creates premature stop codons in about $79 \%$ of cases [17]. As a result, the resulting mRNA are either prematurely degraded or aberrantly spliced, and if it manages to be translated into a protein, it is truncated and non-functional. Thus, exonization events following the insertion of LINE-1 or Alu elements can cause human diseases as described below.

TE insertion can also alter mRNA splicing and cause aberrant alternative splicing leading to exon skipping or intron retention. For example, the insertion of an SVA element into an intron of the TATA box-binding protein-associated factor 1 (TAF1) gene causes X-linked dystonia with parkinsonism (XDP), a movement disorder endemic to the Philippines. The presence of the SVA element prevents normal splicing of TAF1 mRNA and results in retention of intron 32 [18] (Figure 4). However, the real situation is more complex, and a range of alleles exist in the population with varying size expansions of the hexanucleotide repeat domain (CCCTCT)n within the SVA. The length of this repeat is strongly correlated with disease onset, and longer repeat sequences are associated with earlier onset of symptoms [19]. Although the precise role of the length of this hexanucleotide repeat is not entirely clear, it affects the efficiency of retroelement transcription and promotes guanine stacking, a DNA structure known as a G-quadruplex [19].

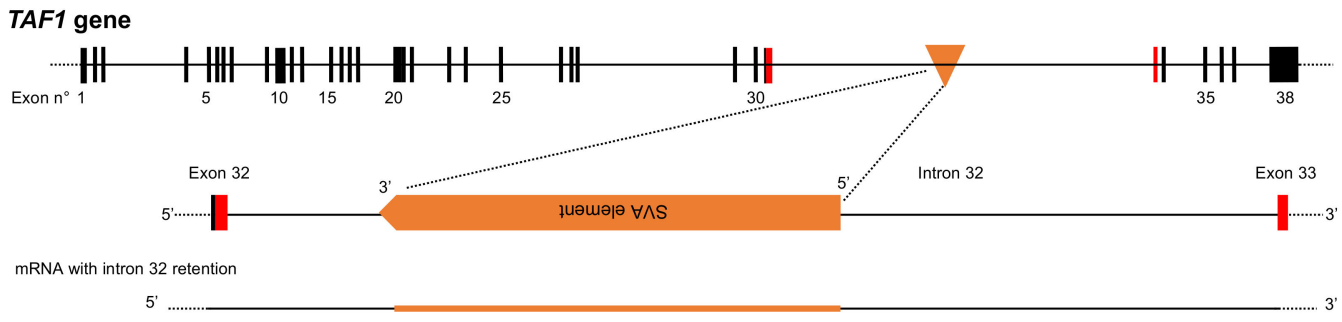

Figure 4. Example of SVA element insertion causing X-linked dystonia with parkinsonism in the TAF1 gene. TAF1 consists of 38 exons (vertical bars; red bars are exons flanking the insertion) with a SVA insertion in reverse orientation in intron 32 (orange triangle). This insertion leads to the retention of intron 32 in the mRNA and the variable number of repeats of the hexanucleotide (CCCTCT)n (see Figure 2c) affects the disease.

As LINE-1 elements include a polyadenylation signal in their own sequence, a polyadenylation signal (i.e., the sequence AATAAA) is frequently created in the A-rich tails of SINE and LINE elements. Therefore, human retroelements, such as LINE-1, Alu, or even HERVs that contain a polyadenylation signal in their LTRs, can introduce intragenic polyadenylation signals, creating new mRNA isoforms. These alternative mRNAs are often truncated by the loss of one or more exons. This modification of polyadenylation sites has been observed in several human diseases as described below. Figure 5 shows the example of the insertion of a LINE-1 element (truncated and partially inverted) in the last exon of the APC gene, causing colon cancer and desmoid tumors (or aggressive fibromatoses) [20].

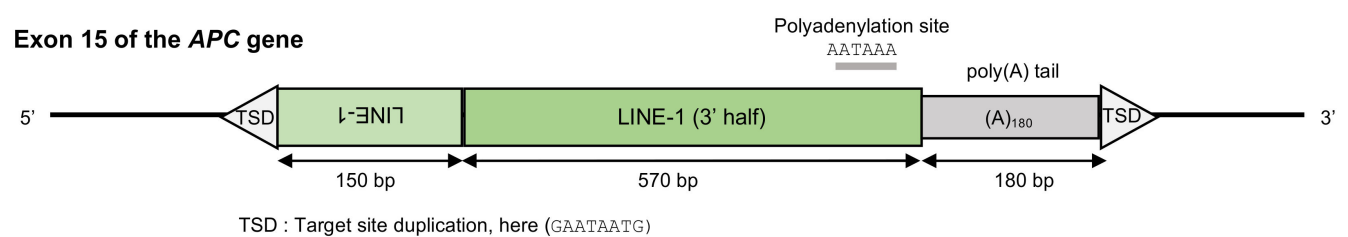

Figure 5. Insertion of a LINE-1 element into the APC gene. The insertion of a truncated and partially inverted LINE-1 element in the last exon of the APC gene results in a new polyadenylation site. 
Finally, the use of regulatory elements provided by the TE insertion is a way to modify gene expression. In particular, the promoter or enhancer/silencer elements of HERV LTRs are particularly powerful. For example, the X-linked form of Opitz syndrome is associated with the presence of an HERV-E element whose LTR acts as a tissue-specific promoter and activator of the MID1 gene [21] (Figure 6).

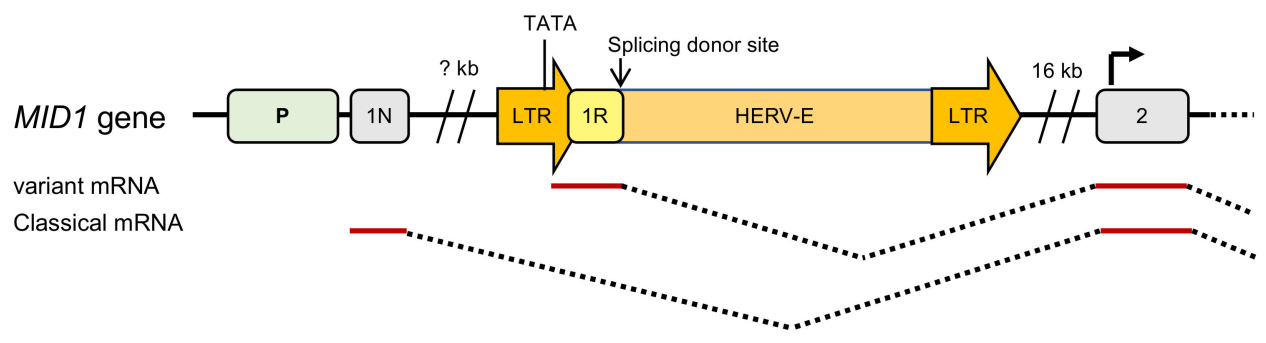

Figure 6. Example of the human endogenous retrovirus (HERV)-E element insertion causing X-linked Opitz syndrome. Schematic structure of the $5^{\prime}$ part of the MID1 gene, including the promoter $(\mathrm{P}$, green box) and the first two introns ( $1 \mathrm{~N}$ and 2, grey boxes). The insertion of the HERV-E element brings a new transcription start site (TATA) and a new intron 1 (1R, yellow box) leading to an alternative transcript (mRNA).

\subsection{Escape from Epigenetic Control}

Because TEs can be considered a threat to genome integrity, host species have developed defense mechanisms to silence them. These mechanisms rely on epigenetic regulatory pathways such as DNA methylation and inhibitory modifications of histone proteins that are achieved, in the case of retrotransposons, through PIWI-interacting RNA (piRNAs) and various protein complexes, as detailed elsewhere [22,23]. In addition, the evolutionary conserved molecular chaperone heat-shock protein-90 (HSP90) also prevent TE jumping and mutagenic effect through its interaction with Piwi proteins [24].

However, these silencing mechanisms are imperfect and some TEs manage to bypass this regulation and are transcribed. For the oldest and/or non-coding TEs, the consequences of this situation may be unimportant but for active TEs, i.e., able to move, a transcription of the TE may lead to new insertions. Nevertheless, even transcripts of a priori inactive elements can have an impact on genome expression in the form of long non-coding RNAs (LncRNAs). Moreover, the relationship between TEs and epigenetic control is two-way, and if DNA hypomethylation is a cause of TE activation, the presence of TEs in a genomic region is also a cause of chromatin hypermethylation. Thus, epigenetic modification of TE regulatory sequences can impact the expression of neighboring genes [25-27].

A correlation between TE activity and chromatin regulation has been observed, primarily at the level of DNA methylation, and DNA hypomethylation is considered a facilitator of TE mobility. As chromatin methylation occurs preferentially at CG dinucleotides called CpG (Cytosine-phosphate-Guanine) islands, the relationship between pathological markers and the methylation status of whole genome CpG islands on the one hand, and LINE-1 elements on the other hand, has been particularly studied in cancers [28-30]. Thus, by analyzing the whole genome of cancer cells of diverse tissue origins, it is possible to observe a preference for insertion of LINE-1 elements in DNA regions with hypomethylation and hypomethylation of the TEs themselves and thus their derepression [31,32].

\subsection{Interaction of TEs with DNA Repair Pathways}

Transposition events generate different types of DNA damage, including single-base mismatches and double strand breaks (DSB), which lead to the activation of DNA damage repair pathways [33]. The transcriptomic study of Wang and Liang in osteosarcoma patients highlighted the correlation between the upregulation of TE expression and the overexpression of 29 genes involved in homologous recombination (HR), non-homologous end joining (NHEJ), and DNA mismatch repair pathways [34]. However, DNA repair 
actors can also act as inhibitors of LINE-1 transposition, suggesting a complex interplay between transposition and DNA damage repair pathways.

Indeed, the regulation of LINE-1 expression and activity is rather complex and includes, but is not limited to, epigenetic controls and interaction with several DNA repair proteins that act as inhibitors of LINE-1 integration in the genome (reviewed in [35]). For example, core proteins of the nucleotide excision repair (NER) pathway, XPD and XPA, the lesion binding protein, XPC, and the endonuclease complex ERCC1-XPF, limits LINE-1 retrotransposition. However, NER proteins may also play a role in the normal LINE-1 insertion process as suggested by the presence of abnormally large duplications at the insertion site in NER-deficient cells [36]. The retrotransposition of LINE-1 is also controlled by proteins involved in postreplicative DNA repair and HR such as ATM and BRCA1. In the case of ATM, the lack or a strong decrease in ATM kinase leads to an increase of LINE-1 activity in neural stem cells [37]. On its side, BRCA1 causes the formation of a target site duplication by initiating double-stranded cleavage, resection and protective coating of DNA ends by replication proteins $\mathrm{A}$, which prevents LINE-1 insertion into the replication fork [38]. The BRCA1 depletion in cells increases LINE-1 activity [38]. In addition, cytoplasmic BRCA1 can inhibit the translation of the open reading frame (ORF)-2 of LINE-1 and the formation of functional LINE-1 ribonucleoprotein [38]. An increased LINE-1 expression and activity was reported in case of defect in Fanconi anemia factors, SLX4/FANCP and FANCD2 [39] In addition, FANCD2 activates the ubiquitin ligase RAD18 leading to the monoubiquitination of the proliferating cell nuclear antigen protein, which interacts with LINE-1 ORF2 during retrotransposition and may therefore inhibit LINE-1 insertion [40]. An interaction of RAD18 with ORF1 has also been found and leads to the formation of P-bodies and stress granules [40]. Finally, overexpression of RAD18 strongly suppressed LINE-1 activity as well as LINE-1-mediated Alu retrotransposition [40].

The high abundance of Alu elements in the human genome creates a major source of non-allelic homologies, which influence DSB repair and lead to altered forms of genetic instability through $A l u$-related repeat mediated deletion (RMD) [41,42]. In addition to their repetitive nature, mismatches between $A l u$ elements also increase the complexity of their interaction with DNA repair processes. Thus, Alu/Alu-related RMD, which relies on the HR mechanism, is the primary repair mechanism in the absence of divergence between Alu sequences, while an alternative NHEJ process takes over when mismatches increase [41,42]. This so-called homeologically induced RMD involves the DNA mismatch repair pathway [42], whereas homology-dependent RMDs, which occur with increased sequence homology, are mainly RAD52-dependent [41]. These data strongly suggest that sequence divergence between the involved Alu elements is a critical selection factor between several competing DNA repair processes [41,42].

\section{Involvement of TEs in Human Cancers}

Whether through the insertion of LINE-1 or Alu elements that cause chromosomal rearrangements or through epigenetic modifications, TEs are widely implicated in the origin of human cancers $[29,30,43-48]$. The role of TEs as a source of genomic instability to induce cancer was also demonstrated experimentally in the zebrafish model of melanoma [49]. The results highlighted a specific upregulation of a LINE and an LTR element in malignant melanomas of transgenic fish. Although this has to be confirmed, TEs expression and methylation levels could be used as prognostic markers [50,51]. Indeed, the quantification of Alu sequence and of LINE-1 methylation may distinguish lung or breast cancer patients from healthy patients [50]. Whole genome sequencing (WGS) of several cancer tissues, i.e., 43 cancer samples from either colorectal, prostate, ovarian, multiple myeloma, and glioblastoma origin, and their matched normal blood samples, pinpointed that LINE-1 and Alu somatic insertions were more frequently observed in cancers of epithelial origin (e.g., colorectal, prostate, and ovarian) compared with blood or brain cancers [52]. Similarly, a previous study of 244 patients with 12 types of cancers showed that colorectal and lung cancers were the most frequently affected by LINE- 1 somatic insertions $(93 \%$ and $75 \%$ of 
patients, respectively) and that, overall, $53 \%$ of patients had at least one somatic insertion of LINE-1 [32]. Furthermore, insertion of TEs (i.e., LINE-1, Alu, SVA, and HERV) was studied in 202 colorectal tumors and the average number of somatic insertions was estimated to be 25 , but with high variability among individuals [53]. Recently, Wang and Liang conducted an integrative analysis of WGS, RNA-seq and methylation data in osteosarcoma patients $(39,37$ and 36 patient samples, respectively) showing upregulation of LINE-1, Alu, SVA and HERV-K [34]. About $80 \%$ of these TE insertions in osteosarcoma are germline insertions. However, among 68 cancer-associated genes (i.e., 32 oncogenes and 36 tumor suppressor genes), 15 have osteosarcoma-specific insertion (Table 1), mainly occurring in transcription factor genes involved in cancer development and neuronal process genes [34]. This study also showcases that three of the 34 patients analyzed for event-free survival had more than $100 \mathrm{TE}$ insertions, suggesting that the greater the number of TE insertions, the longer the event-free survival time [34]. Finally, in colorectal cancer patients, the expression level of some TEs, i.e., nine among SVA, SINE, LINE and HERV families, was correlated with decreased survival [51]. In addition, tumors with the highest TE expression level showed increased immune cell infiltration with upregulation of interferon signaling pathways and increased expression of PD-L1 in immune cells [51].

\subsection{LINE-1 Insertion}

About $50 \%$ of human tumors contain somatic retrotranspositions of LINE-1 elements [32]. The first example of a LINE-1 element insertion was reported as early as 1988 by Morse et al., showing the insertion of a LINE-1 retrotransposon into the human proto-oncogene $c-M Y C$ of human breast carcinoma cells (Table 1) [54]. Comparison of the $c-M Y C$ gene structure of cancer tissue cells and non-cancerous breast cells from the same patient revealed, in the tumor cells, a specific rearrangement of one of the MYC loci and amplification of the second MYC locus located on the homologous chromosome. A LINE-1like sequence was found in the second intron of the rearranged MYC locus. In this case, the LINE-1 sequence functioned as a mobile genetic element to induce a somatic mutation [54]. Another example of somatic insertion of the LINE-1 element was observed in the APC tumor suppressor gene (Figure 4) in several patients with colon cancer and in association with desmoid tumors or aggressive fibromatoses [20]. Whole genome sequencing and transcriptomic data are very useful to study insertions and transcription of TEs, respectively. In this way, a high level of LINE-1 transcription as well as an increase in LINE-1 insertion activity was found in three cancer types, namely primary tumor samples of invasive breast carcinoma, head and neck squamous cell carcinoma, and lung adenocarcinoma [55]. More recently, a genomics study of a set of nearly 3000 tumor samples covering 38 different cancer types highlighted the importance of LINE-1 elements and the genomic remodeling they induce [56]. Indeed, out of nearly 20,000 retrotransposition events observed in these cancer samples, 98\% are due to a LINE-1 element while Alu and SVA elements are only in the very small minority [56]. Finally, by examining four metastatic breast cancer patients, Steely et al. have identified 11 TE insertions or associated structural variants, including three LINE-1, six Alu, and two SVA, and found that the majority of these occurred early in tumor progression [57]. Three main events have been identified: a LINE-1-mediated intergenic deletion, a LINE-1 intronic insertion, and a LINE-1 insertion in an unspecified exon of NIPAL2 gene [57].

\subsection{Insertion of Alu Sequences and Chromosomal Recombination}

As previously mentioned, Alu repeats represent $11 \%$ of the human genome. These repeats are at the origin of non-allelic homologous recombination events, or ectopic recombination, leading to several cancerous diseases (Table 1). These recombination events have several consequences and can lead to chromosomal translocations, deletions or duplications [12,46]. The insertion of an Alu sequence or a deletion resulting from the recombination between $A l u$ sequences can themselves generate an exon skipping [12,46]. 
Atypical teratoid/rhabdoid tumor (AT/RT) is a malignant brain tumor that occurs most commonly in infants and is often associated with a germline alteration of the SMARCB1 gene. A case was recently reported with an $A l u Y$ insertion in exon 2 of the SMARCB1 gene that caused a frameshift truncation absent in the patient's germline [58].

The BRCA1 and BRCA2 genes, which are associated with breast and ovarian cancers, are important sites of $A l u$ element insertion and an unusually high density of $A l u$ repeats is found at these loci. Numerous deletion events have also been reported at the BRCA1 locus and, to a lesser extent, for the BRCA2 gene (reviewed in [46,59]). In addition, one of the first germline mutations caused by a TE to be identified is the insertion of an Alu element in exon 22 of the BRCA2 gene. This insertion results in alternative splicing and skipping of exon 22 in the transcribed RNA [60]. As presented above, Steely et al. searched for a TE insertion in four patients with metastatic breast cancer and found five $A l u$ insertions or associated deletions, all of which are intergenic. Only one event was intragenic, namely an $A l u$-mediated translocation within the third intron of the MAP2K4 gene $(17: 11,974,341 / 22: 48,343,831)$ [57].

Many other cases of deletions caused by recombination between Alu elements have been described $[4,12,13,46]$. For example, homologous recombination between Alu sequences at the Caspase-activated DNase (CAD) gene is frequently detected in human hepatoma tissue. It leads to a deletion of exon-3 which, in turn, leads to the skipping of this exon or its replacement by a partial Alu sequence, producing in both cases a CAD protein truncated in its C-terminal part [61]. A statistically significant overrepresentation of Alu elements around the breakpoints can also be observed in deletions of the cadherin-1 (CDH1) gene [62]. These large deletions are found in $4 \%$ of families with hereditary diffuse gastric cancers and thus seem to originate from homologous recombination between $\mathrm{Alu}$ repeat sequences [62]. It should also be noted that the insertion of Alu elements in the von Hippel-Lindau (VHL) gene is involved in the deletions that cause von Hippel-Lindau disease, an autosomal dominant syndrome that predisposes to the development of benign or malignant tumors [63].

Homologous recombination between Alu elements sometimes results in gene duplication, as has been reported for the $M L L-1$ gene involved in acute myeloid leukemia [64], and the BRCA1 gene and MYB oncogene (reviewed in [12,46]). Duplication of the MYB locus, which encodes an essential transcription factor, is common in human cancers. The human $M Y B$ locus is flanked by Alu repeats that are responsible for its duplication by homologous somatic recombination between adjacent Alu elements located on sister chromatids, as has been observed in T-cell acute lymphoblastic leukemia [65].

Recombination between Alu repeats is also involved in the genesis of the Philadelphia chromosome, i.e., translocation between chromosomes $9 \mathrm{q} 34$ and $22 \mathrm{q} 11$, leading to $B C R / A B L$ gene fusion in chronic myeloid leukemia [66]. Similarly, translocation between chromosomes 5q23-31 and 18q12, involving the TRE-2 oncogene, is due to recombination between Alu elements and plays an important role in the development of Ewing sarcoma [67]. Collectively, these data highlight the role of Alu repeats in mediating genome instability in human cancers.

\subsection{Transcriptional Activity of HERVs}

HERVs have strong transcriptional promoters and enhancers, which can affect the cellular transcriptome, and encode oncoproteins, such as Rec and Np9, that can exert regulatory effects on cell proliferation and cell death balance $[48,68,69]$. Therefore, the transcription of HERVs, especially HERV-K, is linked to many types of cancer, such as breast cancer, melanoma, glioma, Hodgkin's lymphoma, and prostate cancer [48,68-72]. For example, several HERVs loci were found transcriptionally active in Hodgkin's lymphoma cells [70]. Unspliced HERV-H and HERV-K transcripts have been evidenced, and spliced HERV-K transcripts were detected that matched genomic sequences with the expected splicing-donor and splicing-acceptor sites [70]. Especially, HERV-K18 transcription might impact the expression of different isoforms of $C D 48$, which plays multiple stimulatory and 
regulatory roles in the immune system [70]. Montesion et al., showed that the HERV-K promoter activity is present in the majority $(73 \%)$ of breast cancer cell lines tested and that LTR sequence similarity is correlated with promoter expression patterns [71]. In addition, LTR polymorphisms at transcription factor binding sites lead to differential gene expression between individuals [71]. The activation of oncogene expression could be triggered by oncoexaptation as exemplified by the upregulation of IRF5 driven by endogenous retroviral LTR in Hodgkin's lymphoma cells [73]. Moreover, upregulation of the ETV1 oncogene upon HER-V LTR producing chromosomal rearrangements may leads to prostate cancer whereas the cis promoter activation of CSF1R oncogene causes glioblastoma [48]. Finally, HERV-K expression has been mostly studied in breast cancer and melanoma where it could be used as a biomarker and immunological therapeutic target $[69,72,74]$.

Table 1. Examples of cancers and leukemias related to Alu and LINE-1 insertion.

\begin{tabular}{|c|c|c|c|c|}
\hline Cancer or Leukemia & Altered Gene & Involved TE & Type of Event(s) & Reference(s) \\
\hline Acute myeloid leukemia & $M L L 1$ & Alu & Duplication & [64] \\
\hline $\begin{array}{l}\text { Atypical teratoid/rhabdoid } \\
\text { tumor }\end{array}$ & SMARCB1 & Alu $\mathrm{Y}$ & Frameshift & [58] \\
\hline \multirow[b]{2}{*}{ Breast/ovarian cancer } & $B R C A 1$ & Alu & Deletion, duplication & {$[12,59]$} \\
\hline & $B R C A 2$ & Alu & $\begin{array}{l}\text { Duplication, exon skipping, } \\
\text { splicing alteration }\end{array}$ & {$[59,60]$} \\
\hline \multirow{3}{*}{ Breast cancer } & NIPAL2 & LINE-1 & Intronic insertion & [57] \\
\hline & MAP2K4 & Alu & Translocation & [57] \\
\hline & $M Y C$ & LINE-1 & Intronic insertion & [54] \\
\hline Chronic myeloid leukemia & $B C R-A B L$ & Alu & Translocation $\mathrm{t}(9 ; 22)(\mathrm{q} 34 ; \mathrm{q} 11)$ & [66] \\
\hline Colon cancer & $A P C$ & LINE-1 & New polyA site & [20] \\
\hline Ewing sarcoma & EWSR1-ETV & Alu & $\begin{array}{c}\text { Translocation } \\
\mathrm{t}(5 ; 18)(\mathrm{q} 23-31 ; \mathrm{q} 12)\end{array}$ & [67] \\
\hline Hepatoma & $C A D$ & Alu & Deletion & [61] \\
\hline $\begin{array}{l}\text { Hereditary diffuse gastric } \\
\text { cancer }\end{array}$ & $\mathrm{CDH} 1$ & Alu & Deletion & [62] \\
\hline Osteosarcoma & NCOA3, ZNF750 & Alu & Intronic insertion & [34] \\
\hline Osteosarcoma & CSMD1, CNTNAP2, ZHHX3 & $A l u$ and LINE-1 & Intronic insertion & [34] \\
\hline Osteosarcoma & $\begin{array}{c}\text { ADAMTS9-AS2, CTNNA2, } \\
\text { LRP5, NCOR1, OPCML, } \\
\text { PLCB4, PRKN, TFNC }\end{array}$ & LINE-1 & Intronic insertion & [34] \\
\hline Osteosarcoma & KAT6A & LINE-1 & Insertion in $3^{\prime} U T R$-exon & [34] \\
\hline Osteosarcoma & XPC & LINE-1 & Insertion in $5^{\prime}$ UTR-intron & [34] \\
\hline $\begin{array}{l}\text { T-cell acute lymphoblastic } \\
\text { leukemia }\end{array}$ & $M Y B$ & Alu & Duplication & [65] \\
\hline
\end{tabular}

In addition, HERVs are also involved in the aggressiveness of tumors, and are known to be major determinants of pluripotency in human embryonic stem cells and of the reprogramming process of induced pluripotent stem cells [48]. For many tumor types, tumor aggressiveness has been associated with tumor cells obtaining stem cell characteristics. These cancer stem cells possess stem cell properties and sustain tumorigenesis. The CD133 protein is a recognized marker of cancer stem cells, and it has been demonstrated that HERV$\mathrm{K}$ activation is required to expand and maintain a $\mathrm{CD} 133^{+}$melanoma cell subpopulation with stemness features in response to microenvironmental modifications [72].

\subsection{TE-Mediated Epigenetic Alterations}

As mentioned above, the frequent hypomethylation of chromatin in tumor cells is considered a facilitator of TE mobility [28-30]. Thus, it is possible to observe a correlation between the level of chromatin methylation and the rate of insertion and transcription 
of LINE-1 elements in cancer cells [75]. Further demonstration of the role of epigenetic regulation of TEs in cancers is supported by the study of Zhao et al. in the blind mole rat, a small rodent characterized by an unusually long lifespan ( $>21$ years) and resistance to spontaneous and induced tumorigenesis. In these animals, cancer resistance is mediated by retrotransposable elements, and these investigators showed that the animals' cells express very low levels of DNA methyltransferase 1 and, following cell hyperplasia, the DNA of the blind mole rat genome loses its methylation leading to activation of TEs [76]. This mechanism also works, but less strongly, in mice and humans [76]. Retrotransposition events of LINE-1 elements are common in cancers (for example 53\% of patients in [32]) and LINE-1 activity, which fluctuates with tumor progression, and correlates with hypomethylation of the LINE-1 element promoter [32]. More recently, it was reported that LINE-1 hypomethylation was increasingly common with decreasing age of colorectal cancer diagnosis, suggesting a role for global DNA hypomethylation in colorectal cancer in adults younger than 55 years [77]. In addition, LINE-1 hypomethylation was associated with higher colorectal cancer-specific mortality independent of tumor molecular features and patient characteristics [77]. Despite a genome wide hypermethylation in osteosarcoma, the methylation level of $A l u$ and recent LINE-1 was found to be significantly lower in tumor samples than normal osteoblast cell lines [34]. However, no clear correlation appeared between expression of TEs and methylation levels in osteosarcoma [34]. Park et al., showed that $A l u$ index, i.e., quantification of $A l u$ repetitions in cell-free DNA, and LINE-1 methylation level were significantly different in comparison between patients with lung or breast cancer and healthy controls, suggesting that this combination of tests could be implemented to distinguish cancer patients from healthy individuals [50]. LINE-1 methylation levels were also correlated with the human papillomavirus (HPV) status in oropharyngeal squamous cell carcinoma (OPSCC). Indeed, TEs (i.e., LINE-1, Alu and HERVs) were found hypermethylated in OPSCC and the 5-CpG signature distinguished HPV-positive and HPVnegative OPSCC [78]. Especially, LINE-1 methylation levels were higher in HPV-positive cases. However, the hypomethylation of promoter-associated Alu and LTR of HERV leads to the surexpression of ZNF541 and CCNL1 genes, respectively, which is associated with better overall survival [78]. This indicates that TEs are differentially methylated and may regulate gene expression in HPV-positive OPSCC [78].

By contrast, a tumor-suppressive role for LINE-1 has been recently described in acute myeloid leukemia. The authors showed that expression of the chromodomain protein MPP8, which is a chromatin remodeling factor, promotes LINE-1 suppression, and that enhanced LINE-1 silencing is associated with poor prognosis in human acute myeloid leukemia [79].

Escape from epigenetic control of a LINE-1 element can thus lead to cancer as shown in the following example observed in a patient with high-grade mucosal colon adenocarcinoma [80]. Failure to methylate the promoter of the specific LINE-1 locus (L1Hs) involved, located on chromosome 17, allowed RNA transcription in normal tissue samples from the patient. This active element then caused a de novo insertion of the retrotransposon that is assumed to have occurred in the individual's pre-cancerous colonic epithelium. This de novo L1Hs insertion in chromosome 5 disrupted an exon of the APC tumor suppressor gene, producing a trigger mutation that likely caused the subsequent colon cancer. The L1Hs source element on chromosome 17 is a polymorphic structural variant in human populations, and methylation studies in other individuals indicate that this specific locus can be effectively silenced. In the patient, the locus was one of about ten L1Hs that were expressed and all other loci appear to have been silenced. The reason for this specific escape from epigenetic regulation is still unknown [4].

Furthermore, DNA methylation is known to silence HERVs transcription [81], and HERV-K hypomethylation has been associated with poor prognosis in ovarian cancer [68]. Furthermore, hypomethylation in LTR promoters is able to induce carcinogenesis in B cell-derived Hodgkin's lymphoma by deregulating the expression of oncogene protein, namely the colony-stimulating factor 1 receptor [68]. In prostate cancer cells, demethylation 
of the HERV-K promoter in combination with androgen stimulation induces gag mRNA expression [68]. This result suggested the use of combining HERV-K gag expression with prostate-specific antigen testing of blood samples to detect early prostate cancer, especially in high-risk men [68]. HERVs activation is also dependent of histone methylation, especially that of H3K9 by the methyltransferase SETDB1, which is overexpressed in many cancers [82]. In acute myeloid leukemia cells, the loss of SETDB1 gene triggers desilencing of HERVs that leads to the production of double-stranded RNAs with induction of a type I interferon response and, in turn, apoptosis [83]. This suggests that HERVs silencing may be a way for cancer cells to circumvent the immune system [83].

\section{Involvement of TEs in Non-Cancerous Pathologies and Aging}

Apart from cancers, many other human diseases can have a molecular origin in chromosomal recombination, alteration of the structure and/or expression of genes in which TEs are involved (Table 2). These diseases are very diverse and include hemoglobinopathies, metabolic and neurological diseases as well as common diseases $[4,12,13]$.

\subsection{Implications of TEs in Hemoglobinopathies}

The $\alpha$-globin and $\beta$-globin gene clusters, located on chromosomes 16 and 11, respectively, are the target of numerous rearrangements leading to a group of pathologies grouped under the name of hemoglobinopathies, and including thalassemias.

Deletions involving Alu repeats have been observed in the $\beta$-globin gene cluster, which includes the $\gamma-, \delta$-, and $\beta$-globin genes $[84,85]$. For example, in an individual with hereditary persistence of fetal hemoglobin ( $\gamma$-globin), the $\beta$-globin cluster has a large $48.5-\mathrm{kb}$ deletion downstream of the $\beta$-globin gene, and the $5^{\prime}$ breakpoint of the deletion is in a $3^{\prime}$ Alu element of the A $\gamma$-globin gene, one of the two genes (A $\gamma$ and $G \gamma$ ) of fetal globin. However, in this particular case, the recombination mechanism involves non-homologous recombination because the $3^{\prime}$ breakpoint was located in a region that contains various repeats, including part of a LINE-1 repeat, a 160-bp perfect palindrome, and a 41-bp set of direct repeats found at other locations in the human genome [86].

With respect to the $\alpha$-globin gene cluster, recombination events involving Alu- and/or LINE-1 sequences are numerous and, overall, lead to various forms of thalassemia. The following are examples of recombination events that lead to $\alpha$-thalassemia, an inherited hemoglobin disease characterized by quantitative reduction of the $\alpha$-globin chain and anemia. In one family of patients with $\alpha$-thalassemia, there was a $28.5-\mathrm{kb}$ deletion involving Alu repeats that eliminated one of the duplicated $\alpha$-globin genes [85]. In another patient family, an $8.2 \mathrm{~kb}$ deletion in the $\alpha$-globin gene cluster was found. This deletion involved both $\alpha$-globin genes in cis and was caused by a non-homologous recombination event between an Alu element and a LINE-1 element [87]. A large 33-kb deletion encompassing the $\alpha$ - and $\zeta$-globin genes and pseudogenes was observed in another family and caused $\alpha^{0}$-thalassemia, i.e., the complete absence of the $\alpha$-globin protein chain [84].

As described previously for cancer, chromatin structure and/or epigenetic regulation associated with TE insertion can lead to non-cancerous human diseases, but examples are rare to date. However, the $\beta$-globin-L1 allele results from the insertion of an entire LINE-1 element into intron 2 of the $\beta$-globin gene. The decreased transcript level of this $\beta$-globin-L1 allele is due to the hypermethylated profile of its promoter and enhancer sequences, which results in downregulation of transcription and, thus, the $\beta^{+}$-thalassemia phenotype [88].

\subsection{Implications of TEs in Metabolic Diseases and Metabolism Gene-Related Diseases}

Deletions involving Alu repeats account for many mutations in several metabolic genes (Table 2), including the apolipoprotein $B(A P O B)$ gene and the $L D L$ receptor (LDLR) gene. For example, in a patient with homozygous hypobetalipoproteinemia, the deletion of exon 21 of the $A P O B$ gene is the consequence of a recombination event between the Alu sequences of introns 20 and 21, resulting in a nonreciprocal exchange between two chromosomes [89]. The $L D L R$ gene is also a locus of large deletions (or duplications) by 
homologous recombination between Alu repeats, which are numerous in almost all introns of the gene and in the $3^{\prime}$ untranslated region (3'UTR) of the mRNA [90]. For example, analysis of autosomal dominant hypercalcemia in two patient families showed the presence of a large deletion in the $L D L R$ gene due to non-allelic intra-chromosomal homologous recombination between two homologous $A l u$ sequences located away from the splice sites in the intronic sequences [91]. Furthermore, the LINE-1 element can also cause deletions as is the case for the pyruvate dehydrogenase E1 (PDHX) gene located on the X chromosome. In this case, a large $46 \mathrm{~kb}$ deletion linked to the insertion of a full-length LINE-1 element led to a pathological deficiency of the pyruvate dehydrogenase complex [92]. However, insertion of LINE-1 into the PDHX gene can also lead to an aberrantly spliced isoform resulting from the use of two cryptic splice sites [92].

Insertion of $A l u$ or LINE-1 elements can also lead to the creation of a new exon, or exonization (Table 2). For example, a G-to-C mutation in an Alu element present in intron 3 of the ornithine delta-aminotransferase (OAT) gene resulted in the creation of a new splice donor site and potentially a new exon [93]. This insertion of an Alu element also provides a premature transcription termination site and also results in an OAT deficiency. In both cases, this $A l u$ element insertion is involved in mitochondrial OAT deficiency that causes hyperornithinemia leading to chorioretinal gyrate atrophy, a disease characterized by myopia and night blindness progressing to progressive vision loss. Similarly, exon creation due to insertion of an $A l u$ element has been observed in the $\beta$-glucuronidase gene (GUSB) that causes Sly syndrome or mucopolysaccharidosis type VII [94]. The LINE-1 retroelement is also a potential source of exon creation, implicated in at least one case of chronic granulomatous disease, a condition that promotes bacterial and fungal infections [95]. In this case, the X-linked CYBB gene encoding the cytochrome B245 beta chain has an insertion of LINE-1 in intron 5, causing internal rearrangements and new splice sites that result in a highly heterogeneous splicing pattern with the introduction of two LINE-1 fragments as new exons in mRNAs and exon skipping [95].

\subsection{Implications of TEs in Neurological and Psychiatric Diseases}

TE insertion can cause neurological diseases or syndromes [24,96] (Table 2). The insertion of a LINE-1 element in the ribosomal S6 kinase 2 (RSK2) gene was reported in a patient with Coffin-Lowry syndrome, a disease characterized by psychomotor and growth retardation, facial dysmorphism, and skeletal abnormalities. This LINE-1 insertion at position 8 of intron 3 leads to a skipping of exon 4, followed by a reading frame shift and the appearance of a premature stop codon [97]. Ataxia telangiectasia is a rare inherited disorder that affects the nervous system, immune system, and other body systems and which is characterized by progressive difficulty with coordinating movements. An increase in human-specific LINE-1 DNA copy number has been observed in postmortem brain tissue derived from ataxia telangiectasia patients compared with healthy controls [37].

Fabry disease, characterized by central nervous system neurodegeneration, is an $X$-linked recessive disorder of glycosphingolipid catabolism that results from deficient activity of the lysosomal hydrolase $\alpha$-galactosidase A encoded by a gene rich in Alu repeats. Indeed, this gene has twelve Alu elements in its 12-kb sequence [98]. Several mutations and gene rearrangements have been described as causing the disease, of which a single deletion was originally identified as a recombination between $A l u$ repeats and ten others as rearrangements mediated by $A l u$ repeats [98]. Subsequently, a large $3.1 \mathrm{~kb}$ deletion due to $A l u-A l u$ recombination and including the entire exon 2 was identified among 50 novel Fabry disease-causing mutations [99].

Sandhoff disease, a recessive lysosomal storage disease, is another example of a TErelated neurodegenerative disease. Deficiency in $\beta$-hexosaminidase (HEXB) activity is due to deletion alleles of the HEXB gene in $27 \%$ of the dataset examined [100]. The HEXB gene contains two $A l u$ repeats that are involved in the deletion event, which removes approximately $16 \mathrm{~kb}$, including the $H E X B$ gene promoter, exons 1 through 5 , and part of 
intron 5. The deletion also created a reconstituted Alu sequence, with the left half coming from the $5^{\prime}-A l u$ sequence and the right half from the $3^{\prime}$-Alu sequence [100].

Neurofibromatosis type I is a common genetic disease linked to the NF-1 tumor suppressor gene and characterized by changes in skin coloration and the growth of benign tumors along the nerves, i.e., neurofibromas. Insertion of an $A l u$ sequence into the intron of the NF-1 gene results in deletion and frameshift in the downstream exon upon splicing, which may be a cause of the disease [101].

High expression of TEs has been observed in several human neurodegenerative diseases, including sporadic Creutzfeldt-Jakob disease, age-related macular degeneration, and amyotrophic lateral sclerosis (ALS) [96]. For example, the RNA-binding protein TDP-43, which is implicated in ALS and frontotemporal lobar degeneration (FTLD), interacts with many TE transcripts, and this association of TDP-43 with its target TE RNAs is reduced in FTLD patients [102]. As mentioned previously, insertion of a SVA element into an intron of the TAF1 gene causes XPD [19] (Figure 3). The insertion prevents normal mRNA splicing and results in retention of intron 32 [18]. Furthermore, this SVA insertion specifically reduces acetylated histone $\mathrm{H} 3$ binding on exon 32, which is closest to the insertion. Conversely, excision of the SVA by CRISPR/Cas9 technology restores acetylated histone $\mathrm{H} 3$ binding [103].

By using two independent murine models for endogenous retrovirus (ERV) activation, namely intracerebroventricular injection of streptozotocin and the muMT strain lacking $B$ cells and antibody production, Sankowski et al. found that induced hippocampal ERV activation was accompanied by a significant hippocampus-related memory impairment in both models [104]. These results suggest a role for ERVs as endogenous drivers of cognitive deficit in humans. In addition, this study also showed that cognitive deficits are attenuated in the absence of mitochondrial antiviral signaling proteins, which are retroviral RNA-sensing proteins, suggesting that these proteins may be therapeutic targets to treat dementia and neuropsychiatric disorders [104].

A link between TEs and psychiatric disorders has also been demonstrated [105-107]. In particular, whole-genome sequencing revealed brain tissue-specific insertions of LINE-1 in patients, preferentially located in synapse-related and schizophrenia-related genes, suggesting a causal role of LINE-1 in disease development [107,108]. Moreover, expression of HERVs in blood and cerebral spinal fluid was observed in individuals with schizophrenia $[107,109]$. The involvement of TEs was also reported for affective disorders [110], stress-related psychiatric disorders [107,111], and post-traumatic stress disorder [107]. One study also found hypomethylation of LINE-1 in bipolar individuals [108]. Finally, the involvement of TEs has been reported in several cases of autism spectrum disorder (ASD) [107]. The increased expression of LINE-1 has been observed in post-mortem cerebellum of ASD individuals compared to matched controls but not in the three other cortical brain regions studied [112]. The creation of a permissive state for LINE-1 activity in the cerebellum in ASD could be due to decreased binding of methyl-CpG-binding protein 2 to the $5^{\prime}$ UTR of LINE-1, leading to ORF 1 downregulation accompanied by reduced H3K9me3 levels in the cerebellum in the ASD group but not in healthy controls [112]. LINE-1 was also shown to be hypomethylated in lymphoblastoid cells derived from a subset of ASD patients [113]. In addition, Alu methylation status was shown to vary by ASD subtype, suggesting a role for Alu elements [114].

Finally, major depressive disorder, commonly known as depression, is a debilitating but common illness with both genetic and environmental risk factors. It has been hypothesized that exposure to either exogenous viruses or traumatic experiences can activate HERVs in the brain to cause depressive symptoms [115]. In addition, a second hypothesis is that individual differences in vulnerability or resilience result from the balance of activated HERVs with pathogenic versus protective functions in the brain [115]. However, these hypotheses have to be demonstrated experimentally. 


\subsection{Implications of TEs in Various Other Diseases}

Alveolar capillary dysplasia with misalignment of pulmonary veins is a rare and lethal neonatal developmental lung disorder caused by point mutations or copy-number variant deletions of the FOXF1 gene, or its distant tissue-specific enhancer, often due to the presence of TE insertion. Indeed, breakpoints sequencing of causative deletion showed that half are Alu-mediated deletion and 30\% displayed a LINE-1 sequence at least at one of the two breakpoints [116]. The FOXF1 locus at 16q24.1 is a large genomic instability hotspot including two evolutionary young LINE-1, namely L1PA2 and L1PA3, flanking five Alu sequences (i.e., AluY, two AluSx, AluSx1, and AluJr) related to the disease [116].

Alternative splicing is often affected by insertion of TEs and, for example, insertion of the Alu element into an intron of the human factor VIII (F8) gene leads to exon skipping and, consequently, to the development of hemophilia A [117]. Another example is the insertion of an Alu element in exon 9, or just at the beginning of exon 9, of the fibroblast growth factor receptor 2 (FGFR2) gene, which may be a cause of Apert syndrome [118]. The latter mutation affects the use of the $3^{\prime}$ splice site, leading to the genesis of different nonfunctional splice forms of FGFR2 gene transcripts. By contrast, exon creation following insertion of an Alu element in the type IV collagen alpha-3 chain gene (COL4A3) may be the cause of Alport syndrome, a nephropathy (glomerulonephritis) due to a defect in collagen IV [119].

The dystrophin gene $(D M D)$, located on chromosome $X$, is a giant gene of about $2.5 \mathrm{Mb}$ in size with more than 60 exons. Numerous TE insertions into the DMD gene have resulted in deletions or exon skipping. For example, the insertion of LINE-1 induces the skipping of exon 44, which causes Duchenne muscular dystrophy [120]. Insertion of an Alu-like sequence downstream of intron 11 of the $D M D$ gene has been observed in individuals with X-linked dilated cardiomyopathy [121]. This insertion induces a rearrangement that activates a cryptic splice site in intron 11 and produces an alternative transcript containing the $A l u$-like sequence and part of the adjacent intron 11, spliced between exons 11 and 12 but not translated because of the presence of many stop codons [121]. Other examples of exon skipping due to Alu or LINE-1 insertion include the OPA1 gene involved in autosomal dominant opticatrophy [122], the FKTN gene responsible of Fukuyama-type congenital muscular dystrophy [123], and the IDS gene involved in Hunter syndrome [124] (Table 2). Alternative splicing alteration and an open reading frame shift are also involved in X-linked retinitis pigmentosa owing to LINE-1 insertion in the RP2 gene [125].

In addition, several diseases have been linked to the introduction of a novel polyadenylation site by insertion of LINE-1 or Alu elements into human genes, such as hemophilia A and B [126], autoimmune lympho-proliferative syndrome [127], X-linked dilated cardiomyopathy [121], hypocalciuric hypercalcemia [128], and severe neonatal hyperparathyroidism [128] (Table 2).

The increased expression of TEs may also promote the recruitment of inflammatory processes and the disruption of immunological balance, which can lead to chronic inflammation in idiopathic pulmonary fibrosis (IPF) [129]. Indeed, these authors observed TE dysregulation in the alveolar type II lung cells and alveolar macrophages of IPF patients and the increased TE, especially LINE-1, expression is positively correlated with both the activation of cellular TE inhibitors and the innate immune response and negatively correlated with autophagy in IPF [129]. The involvement of HERVs in innate immunity has been also demonstrated and HERVs contribute to pro-inflammatory diseases such as Type-I diabetes, autoimmune disorders and multiple sclerosis, as well as neuropathogenesis of severe acute respiratory syndrome coronavirus-2 (SARS-CoV-2) [130]. Finally, the mutual interaction between microbiote and HERVs expression was highlighted in humans by a strong correlation between the expression of HERV-H, $-\mathrm{K}$ and $-\mathrm{W}$, and the concentration of Bifidobacterium spp. in the gut $[130,131]$. Moreover, the expression of ERVs was found to be favored by the skin microbiota as shown by using mouse keratinocyte model challenged by various skin commensals [132]. 
Table 2. Examples of non-cancerous diseases related to TE insertion.

\begin{tabular}{|c|c|c|c|c|}
\hline Disease or Syndrome & Altered Gene & Involved TE & Type of Event(s) & Reference(s) \\
\hline Alport syndrome & COL4A3 & Alu & Exonization & [119] \\
\hline $\begin{array}{l}\text { Alveolar capillary dysplasia with } \\
\text { misalignment of pulmonary veins }\end{array}$ & FOXF1 & Alu, LINE-1 & Deletion & [116] \\
\hline Apert syndrome & FGFR2 & Alu & Exon skipping, aberrant splicing & [118] \\
\hline $\begin{array}{l}\text { Autoimmune lympho-proliferative } \\
\text { syndrome }\end{array}$ & FAS & Alu & Exon skipping, new poly(A) site & [127] \\
\hline Autosomal dominant opticatrophy & OPA1 & Alu & Exon skipping & [122] \\
\hline Chronic granulomatous disease & $C Y B B$ & LINE-1 & Exonization, intron retention & [95] \\
\hline Coffin-Lowry syndrome & RPS6KA3 & LINE-1 & Exon skipping, frameshift & [97] \\
\hline Duchenne Muscular Dystrophy & $D M D$ & LINE-1 & Exon skipping & [120] \\
\hline Fabry disease & $a-G A L A$ & Alu & Deletion & {$[98,99]$} \\
\hline Familial hypercholesterolemia & $L D L R$ & Alu & Deletion & [91] \\
\hline Fanconi anemia & UBE2T & Alu & Deletion, duplication & [14] \\
\hline $\begin{array}{l}\text { Fukuyama-type congenital } \\
\text { muscular dystrophy }\end{array}$ & FKTN & LINE-1 & Exon skipping & [123] \\
\hline Hemophilia A & F8 & Alu & Exon skipping & [117] \\
\hline Hemophilia B & $F 9$ & Alu, LINE-1 & New poly(A) site & [126] \\
\hline Hunter syndrome & IDS & Alu & Exon skipping & [124] \\
\hline Hypo beta lipoproteinemia & $A P O B$ & Alu & Deletion & [89] \\
\hline $\begin{array}{c}\text { Hypocalciuric hypercalcemia and } \\
\text { neonatal severe } \\
\text { hyper-parathyroidism }\end{array}$ & CASR & Alu & New poly(A) site & [128] \\
\hline Multiple sclerosis & CD58 & Alu & Exon skipping, frameshift & [133] \\
\hline Neurofibromatosis type 1 & NF1 & Alu & Aberrant splicing, frameshift & [101] \\
\hline Opitz syndrome & MID1 & HERV-E & New regulatory region & [21] \\
\hline $\begin{array}{l}\text { Ornithine delta-aminotransferase } \\
\text { deficiency }\end{array}$ & OAT & Alu & Exonization & [93] \\
\hline $\begin{array}{l}\text { Pyruvate dehydrogenase complex } \\
\text { deficiency }\end{array}$ & PDHX & LINE-1 & Aberrant splicing, deletion & [92] \\
\hline Sandhoff disease & HEXB & Alu & Deletion & [100] \\
\hline Sly syndrome & GUSB & Alu & Exonization & [94] \\
\hline Thalassemia & $H B B$ & Alu & $\begin{array}{l}\text { Deletion, promoter } \\
\text { hypermethylation }\end{array}$ & [84-88] \\
\hline Von Hippel Lindau disease & VHL & Alu & Deletion & [63] \\
\hline X-linked dilated cardiomyopathy & $D M D$ & Alu, LINE-1 & $\begin{array}{l}\text { New poly(A) site, aberrant } \\
\text { splicing }\end{array}$ & [121] \\
\hline $\begin{array}{l}\text { X-linked dystonia with } \\
\text { parkinsonism }\end{array}$ & TAF1 & SVA & Intron retention & {$[18,19]$} \\
\hline X-linked retinitis pigmentosa & $R P 2$ & LINE-1 & Aberrant splicing, frameshift & [125] \\
\hline
\end{tabular}

\subsection{TEs and Common Diseases Relationship}

The increase in genomic studies and, in particular, Genome-Wide Association Studies (GWAS) strengthens the case for a genetic basis for common diseases, i.e., diseases that have a high incidence in the population $(>1: 2000)$ and are not usually classified as hereditary diseases. However, these diseases often have a genetic basis and a family aggregation can be observed. They are called multifactorial diseases since, in addition to genetic predisposition factors, a complex set of environmental factors (food, viral and bacterial infections, other diseases, exposure to pollutants, smoking, alcohol and drugs) affect development of the pathology. These common diseases are very varied and include cardiovascular diseases (hypertension, myocardial infarction, among others), endocrine 
diseases (type 2 diabetes, obesity and hypercholesterolemia), osteoarticular pathologies (osteoarthritis, osteoporosis) neurological diseases (senile dementia), dysimmune and autoimmune diseases (e.g., multiple sclerosis), psychiatric diseases (schizophrenia, bipolar disorder, autism) and allergy/asthma problems. Hundreds of different insertions of $A l u$ elements have been identified in the best-defined predisposition loci or genes for these diseases [134]. Furthermore, in many cases, the mobile element insertion is in linkage disequilibrium with disease haplotype markers, i.e., the $A l u$ element appears linked to single nucleotide polymorphisms (SNPs) associated with the disease. This suggests that the TE insertion is likely to be associated with, or even cause, the genetic risk factor for developing the disease in question.

An example is the insertion of an $A l u$ element at the CD58 locus on a haplotype that affects susceptibility to multiple sclerosis (MS). Of the many risk alleles identified by GWAS for this disease, the CD58 genotype is one of the strongest genetic indicators of MS risk. The risk allele reduces the expression of the CD58 gene and this reduction in CD58 expression is associated with the risk of developing MS and relapsing. In-depth sequence study of this locus showed a very strong genetic link between a $302 \mathrm{bp}$ Alu insertion and a particular SNP (namely rs2300747). Only this allele of the CD58 locus with both the Alu insertion and the rs2300747 SNP is associated with an increased risk of developing the disease. This $A l u$ insertion is relatively frequent since it is present in $66 \%$ of individuals. Furthermore, this $A l u$ sequence insertion alters CD58 mRNA splicing, promoting exon 3 skipping and a reading frame shift leading to a non-functional mRNA [133]. These observations thus show that routine insertion of an Alu sequence compromises CD58 gene expression, creating an allele that increases susceptibility to MS. More generally, it can thus be concluded that inherited TE insertion alleles, which are common to all our genomes, can modify the risk of developing many types of common disease.

\subsection{TEs and Aging}

Finally, TE transposition can lead to mutations and damage to DNA. Double-strand breaks, which can be caused by transposition [33], are one of the processes directly related to aging. Thus, TEs can be considered an internal source of aging and the frequency of transposition can, in turn, affect the rate of aging [23]. The PIWI-piRNA pathway appears as the main link between TEs and aging. Although the primary mechanism for this connection appears to be repression of transposition-generated double-strand breaks, PIWI-piRNAdirected DNA methylation and changes in PIWI-piRNA-associated histone modifications are two other mechanisms linking the PIWI-piRNA pathway and aging [23]. Nevertheless, further experiments are needed to determine the extent of the role of TEs relative to other sources of DNA damage or different causes of aging. The putative role of TEs in aging is further supported by a recent study in mice, which shows that TE expression increases with age in the brain of 20-month-old mice [135]. Of the differentially expressed TEs in the mouse brain at twenty months, $92.7 \%$ increase with age. The LTR family is particularly affected and ERV is the predominant family of LTR retrotransposons that increases with age [135]. In addition, the longevity regulatory protein, SIRT6, appeared as a potent silencer of LINE-1 in mice, and its depletion during aging, or following DNA damage, allows the reactivation of LINE-1 [136]. Specifically, SIRT6 binds to the 5'UTR of LINE-1 and causes mono-ADP ribosylation of the corepressive nuclear protein, KAP1, which facilitates the interaction of KAP1 with the heterochromatin factor, HP1a, and thus contributes to the enclosure of LINE-1 elements into the transcriptionally repressive heterochromatin [136]. The increase of TEs expression or TE activation, especially that of LINE-1 and HERVs, may be broadly impacted by Alzheimer disease and/or Tau pathologies in human brains [137-139].

\section{Role of Stress and Environmental Pollution in TE Mobility and Disease Onset}

In plants and animals, different forms of stress are known to act as triggers or facilitators of TE mobility [140,141]. Several studies in plants have reported overexpression of TEs following abiotic or biotic stress conditions such as temperature, nitrate de- 
privation, and wounding [142-145]. Activation of TEs in response to different stresses has also been demonstrated in insects [146], and especially in the context of insecticide resistance [147-149]. This suggests that human exposure to pesticides and other environmental pollutants could act on the mobility of TEs in humans and be the cause of certain pathologies such as cancers.

To date, there is no direct demonstration of a causal relationship between exposure to a pollutant, TE mobility and development of a pathology. However, the arguments in favor of this hypothesis are of two types: (i) it has been shown experimentally or in population studies that pesticides and other environmental contaminants can modify the different levels of epigenetic regulation and thus create a context favorable to the mobility of TEs; (ii) mobility tests conducted on human or rodent cell models have shown that exposure to different contaminants or stresses can promote the mobility of TEs, in particular of LINE-1 elements [150].

\subsection{Epigenetic Alterations Caused by Environmental Pollutants}

Pesticides of various classes can cause epigenetic modifications such as DNA demethylation and histone modification. Several animal studies have shown hypomethylation of certain promoters after exposure to high doses of pesticides (e.g., organochlorines, biphenyl-polychlorines, methyl-mercury). In addition, dichlorodiphenyltrichloroethane (DDT) is known to modify the DNA methylation profile, in particular in the brain of young rats where DDT-induced hypomethylation suggests a role for this pesticide in neurodegenerative diseases [151]. Metoxychlor, an organochlorine pesticide acting as an endocrine disruptor also alters methylation patterns leading to reproductive defects in female offspring [152]. The methylation of all the genes tested is affected, and these changes are transmitted to the offspring because only the gametes are affected, but they gradually disappear between the first and third generation [152]. The endocrine disruptor di(2-ethylhexyl)phthalate (DEHP) interferes with sex hormones signaling pathways and induces testicular dysgenesis syndrome depending on the mouse strain [153]. This transgenerational endrocrine disruption effect could be explained by the existence of SNPdependent mechanisms and a DHEP-induced increase of the Svs3ab promoter methylation persisting across generations [153]. Previously, DEHP was reported to induce an increase in mir-615 microRNA expression and a genome-wide decrease in microRNA promoter methylation as well as methylation-associated silencing of almost the entire cluster of the seminal vesicle secretory proteins and antigen genes, which are known to play a fundamental role in sperm physiology [154].

In humans, global DNA hypomethylation, as measured by the \% of 5-methyl-Cytosine at the Alu and LINE-1 sequences in adipocytes where xenobiotics are concentrated, has been linked to low-dose exposure to organochlorine pesticides in healthy individuals [155]. The same correlation between levels of persistent organic pollutants (DDT, DDE, $\beta$-BHC, oxychlordane, mirex) or polychlorinated biphenyls in blood and overall DNA hypomethylation was observed in another population [156]. Results from a cohort study showed that prenatal exposure to persistent organic pollutants (POPs), including organochlorine pesticides, polybrominated diphenyl ethers, and polychlorinated biphenyls, alter the DNA methylation level of LINE-1 and imprinted genes in placenta [157]. Especially, elevated concentrations of $\beta$-hexachlorhexane in maternal serum collected during delivery were significantly associated with a decrease in methylation of LINE-1 in the placenta [157]. A cross-sectional study was conducted using the data of 444 individuals (253 men and 191 women) exposed to sixteen different POPs, including six organochlorine pesticides and ten polychlorinated biphenyls. The correlation between POPs level in serum and DNA methylation of Alu and LINE-1 in peripheral leukocytes was assessed and the results showed that several POPs were associated with global DNA hypomethylation in the Alu assay for men and global DNA hypermethylation in the LINE-1 assay for women [158].

Exposure to pesticides may increase the risk of cancers, perhaps mediated in part through global alterations of DNA methylation. In order to evaluate alterations of LINE-1 
methylation by pesticides in a variety of classes, data from 596 cancer-free male participants enrolled in the Agricultural Health Study (AHS) were used to examine associations between use of 57 pesticides and LINE-1 methylation in peripheral blood leucocytes [159]. The results of this study showed that prior application of 10 pesticides was positively associated and prior application of eight pesticides was negatively associated with LINE1 methylation. In dose-response analyses with specific pesticides, increase in LINE-1 methylation was observed with increases in five pesticides, namely imazethapyr, fenthion, S-ethyl- $N, N$-dipropylthiocarbamate, butylate, and heptachlor, whereas a decrease in LINE1 methylation was noticed with increases in three pesticides, namely carbaryl, chlordane, and paraquat [159].

Comparing LINE-1 methylation in 50 rural sprayers and 50 urban workers exposed to unspecified pesticides, the authors observed a more pronounced hypomethylation of LINE-1 for most genotypes, and hypermethylation of some heterozygous genotypes in the urban group compared with the rural group [160]. This suggest that urbanization could play an additional risk for epigenetic changes associated with pesticide exposure [160]. Arsenic is also a common pollutant in the waters of some countries and its impact on methylation, especially at the level of LINE-1 elements, has been evaluated in many studies, sometimes contradictory [161]. Therefore, modification of the DNA methylation rate and in particular the hypomethylation of the Alu and LINE-1 sequences by pesticides and other pollutants represents a very probable mechanism of reactivation of TEs and consequently of induction of pathologies such as cancers [12,43].

Furthermore, histone modification is also a possible mechanism of human pesticide toxicity. In particular, an increase in histone acetylation ( $\mathrm{H} 3$ and $\mathrm{H} 4)$ has been shown following treatment of neuronal cells with the herbicide Paraquat and the insecticide Dieldrin $[162,163]$. The organochlorine pesticide chlordecone, which displays well-recognized estrogenic properties, was also reported to modify the methylation level of histone $\mathrm{H} 3$ on lysine 4 and 9 (H3K4m3 and H3K9me3, respectively) in human cord blood and human cord KE-37 cell line [164].

\subsection{Methylation Status of LINE-1 as a Marker of Environmental Pollution}

The methylation status of LINE-1 compared to that of specific genes is often used as a marker of epigenetic alteration following pollutant exposure. For example, strong ligands of the aryl hydrocarbon receptor (AhR) such as such as 6-formylindolo [3,2-b]carbazole, 3-methylcholantrene and benzo[a]pyrene are known to induce hypomethylation of LINE-1 and then increase LINE-1 mRNA expression through the mitogen-activated protein kinase (MAPK) in breast cancer cell line and through the transforming growth factor- $\beta 1$ (TGF$\beta 1) /$ Smad pathway in HepG2 hepatocarcinoma cell line [165]. Exposure to weak AhR ligands such as hexachlorobenzene and chlorpyrifos also reduce LINE-1 methylation levels and induce LINE-1 reactivation, i.e., increased mRNA expression, in both MDA-MB-231 breast cancer cells and non-tumoral breast epithelial cells (i.e., NMuMG cell line) [165]. However, the basal expression of LINE-1 was significantly higher in the MDA-MB-231 cell lines compared to NMuMG non-tumoral cells [165]. In addition, the decrease of H3K9me3 level in chlordecone-exposed samples was associated with a decreased methylation in LINE-1 promoters, increased presence of $\mathrm{H} 3 \mathrm{~K} 4 \mathrm{me} 3$, and then increased expression of LINE-1 ORF-1 and -2 [164].

\subsection{Mobility of LINE-1 Elements in Response to Environmental Pollution}

The use of mobility assays for LINE-1 elements using cells transfected with modified LINE-1 elements containing a reporter gene and the estimation of the copy number are valuable approaches to assess the impact of a stress or an environmental pollutant on the activity of LINE-1. These approaches, which are still not widely used, are being developed and allow us to conclude that environmental pollutants have a strong impact on the activity of LINE-1 elements and, by extension, on all TEs. Thus, many pollutants have been tested for their ability to activate the mobility of LINE-1 elements in different human or animal 
cellular models [150]. It was found that metals such as aluminum, arsenic, cadmium, mercury and nickel cause an increase in LINE-1 retrotransposition events, whereas cobalt, lead, magnesium and zinc have no effect. Copper even seems to have an inhibitory effect [166]. However, it is important to note that these metals were tested alone and that it may be interesting to analyze the effects of mixtures since this is what humans are most often exposed to. Carcinogens such as benzo[a]pyrene, phorbol esters, or heterocyclic amines also seem to be able to induce the mobility of LINE-1 elements although the results, obtained on mouse models, are not necessarily generalizable to humans [150].

\section{Conclusions}

Initially considered as junk DNA, TEs are now recognized as major players in genome evolution, and their role in genome plasticity has been clearly demonstrated. The high abundance of TEs in the human genome, in particular the Alu and LINE-1 repeats, makes them responsible for the molecular origin of several diseases. This involves several molecular mechanisms, in addition to the insertion of TEs per se, including DNA recombination and chromosomal rearrangements (especially deletion); modification of gene expression by introduction or modification of poly-A sites, splice sites, exons or introns and regulatory elements, as well as alteration of epigenetic regulations. Therefore, improving our knowledge of TEs through deep genomic approaches may lead to new potential diagnostic markers of diseases and prenatal markers of genetic diseases. Thus, the development of combined molecular (i.e., next generation sequencing and whole genome sequencing) and bioinformatics tools is of great interest despite mostly used in the cancer field $[32,34,50,55,56,113,130,167-169]$. Finally, the exposure of individuals to numerous stresses and in particular to environmental pollutants and contaminants seems to have a non-negligible impact on the epigenetic derepression and mobility of TEs, which can lead in this way to the development of certain pathologies such as cancers, neurological or autoimmune diseases.

Funding: This research received no external funding.

Institutional Review Board Statement: Not applicable.

Informed Consent Statement: Not applicable.

Data Availability Statement: Not applicable.

Conflicts of Interest: The author declares no conflict of interest.

\section{References}

1. Lander, E.S.; Linton, L.M.; Birren, B.; Nusbaum, C.; Zody, M.C.; Baldwin, J.; Devon, K.; Dewar, K.; Doyle, M.; FitzHugh, W.; et al. Initial Sequencing and Analysis of the Human Genome. Nature 2001, 409, 860-921. [CrossRef]

2. de Koning, A.P.J.; Gu, W.; Castoe, T.A.; Batzer, M.A.; Pollock, D.D. Repetitive Elements May Comprise over Two-Thirds of the Human Genome. PLoS Genet. 2011, 7, e1002384. [CrossRef] [PubMed]

3. Wicker, T.; Sabot, F.; Hua-Van, A.; Bennetzen, J.L.; Capy, P.; Chalhoub, B.; Flavell, A.; Leroy, P.; Morgante, M.; Panaud, O.; et al. A Unified Classification System for Eukaryotic Transposable Elements. Nat. Rev. Genet. 2007, 8, 973-982. [CrossRef] [PubMed]

4. Burns, K.H. Our Conflict with Transposable Elements and Its Implications for Human Disease. Annu. Rev. Pathol. 2020, 15, 51-70. [CrossRef]

5. Konkel, M.K.; Walker, J.A.; Batzer, M.A. LINEs and SINEs of Primate Evolution. Evol. Anthropol. Issues News Rev. 2010, 19, 236-249. [CrossRef]

6. Bourque, G.; Burns, K.H.; Gehring, M.; Gorbunova, V.; Seluanov, A.; Hammell, M.; Imbeault, M.; Izsvák, Z.; Levin, H.L.; Macfarlan, T.S.; et al. Ten Things You Should Know about Transposable Elements. Genome Biol. 2018, 19, 199. [CrossRef] [PubMed]

7. Wang, L.; Jordan, I.K. Transposable Element Activity, Genome Regulation and Human Health. Curr. Opin. Genet. Dev. 2018, 49, 25-33. [CrossRef] [PubMed]

8. Dewannieux, M.; Harper, F.; Richaud, A.; Letzelter, C.; Ribet, D.; Pierron, G.; Heidmann, T. Identification of an Infectious Progenitor for the Multiple-Copy HERV-K Human Endogenous Retroelements. Genome Res. 2006, 16, 1548-1556. [CrossRef] [PubMed] 
9. Thomas, J.; Perron, H.; Feschotte, C. Variation in Proviral Content among Human Genomes Mediated by LTR Recombination. Mob. DNA 2018, 9, 36. [CrossRef] [PubMed]

10. Senft, A.D.; Macfarlan, T.S. Transposable Elements Shape the Evolution of Mammalian Development. Nat. Rev. Genet. 2021, 22, 691-711. [CrossRef]

11. Nicolau, M.; Picault, N.; Moissiard, G. The Evolutionary Volte-Face of Transposable Elements: From Harmful Jumping Genes to Major Drivers of Genetic Innovation. Cells 2021, 10, 2952. [CrossRef] [PubMed]

12. Chénais, B. Transposable Elements in Cancer and Other Human Diseases. Curr. Cancer Drug Targets 2015, 15, 227-242. [CrossRef]

13. Hancks, D.C.; Kazazian, H.H. Roles for Retrotransposon Insertions in Human Disease. Mob. DNA 2016, 7, 9. [CrossRef] [PubMed]

14. Rickman, K.A.; Lach, F.P.; Abhyankar, A.; Donovan, F.X.; Sanborn, E.M.; Kennedy, J.A.; Sougnez, C.; Gabriel, S.B.; Elemento, O.; Chandrasekharappa, S.C.; et al. Deficiency of UBE2T, the E2 Ubiquitin Ligase Necessary for FANCD2 and FANCI Ubiquitination, Causes FA-T Subtype of Fanconi Anemia. Cell Rep. 2015, 12, 35-41. [CrossRef]

15. Kidd, J.M.; Graves, T.; Newman, T.L.; Fulton, R.; Hayden, H.S.; Malig, M.; Kallicki, J.; Kaul, R.; Wilson, R.K.; Eichler, E.E. A Human Genome Structural Variation Sequencing Resource Reveals Insights into Mutational Mechanisms. Cell 2010, 143, 837-847. [CrossRef] [PubMed]

16. Rodić, N.; Zampella, J.G.; Cornish, T.C.; Wheelan, S.J.; Burns, K.H. Translocation Junctions in TCF3-PBX1 Acute Lymphoblastic Leukemia/Lymphoma Cluster near Transposable Elements. Mob. DNA 2013, 4, 22. [CrossRef] [PubMed]

17. Sela, N.; Mersch, B.; Gal-Mark, N.; Lev-Maor, G.; Hotz-Wagenblatt, A.; Ast, G. Comparative Analysis of Transposed Element Insertion within Human and Mouse Genomes Reveals Alu's Unique Role in Shaping the Human Transcriptome. Genome Biol. 2007, 8, R127. [CrossRef] [PubMed]

18. Aneichyk, T.; Hendriks, W.T.; Yadav, R.; Gao, D.; Vaine, C.A.; Collins, R.L.; Domingo, A.; Currall, B.; Stortchevoi, A.; Multhaupt-Buell, T.; et al. Dissecting the Causal Mechanism of X-Linked Dystonia-Parkinsonism by Integrating Genome and Transcriptome Assembly. Cell 2018, 172, 897-909.e21. [CrossRef]

19. Bragg, D.C.; Mangkalaphiban, K.; Vaine, C.A.; Kulkarni, N.J.; Shin, D.; Yadav, R.; Dhakal, J.; Ton, M.-L.; Cheng, A.; Russo, C.T.; et al. Disease Onset in X-Linked Dystonia-Parkinsonism Correlates with Expansion of a Hexameric Repeat within an SVA Retrotransposon in TAF1. Proc. Natl. Acad. Sci. USA 2017, 114, E11020-E11028. [CrossRef]

20. Miki, Y.; Nishisho, I.; Horii, A.; Miyoshi, Y.; Utsunomiya, J.; Kinzler, K.W.; Vogelstein, B.; Nakamura, Y. Disruption of the APC Gene by a Retrotransposal Insertion of L1 Sequence in a Colon Cancer. Cancer Res. 1992, 52, 643-645. [PubMed]

21. Landry, J.-R.; Rouhi, A.; Medstrand, P.; Mager, D.L. The Opitz Syndrome Gene Mid1 Is Transcribed from a Human Endogenous Retroviral Promoter. Mol. Biol. Evol. 2002, 19, 1934-1942. [CrossRef]

22. Huang, S.; Yoshitake, K.; Asakawa, S. A Review of Discovery Profiling of PIWI-Interacting RNAs and Their Diverse Functions in Metazoans. Int. J. Mol. Sci. 2021, 22, 11166. [CrossRef]

23. Lenart, P.; Novak, J.; Bienertova-Vasku, J. PIWI-PiRNA Pathway: Setting the Pace of Aging by Reducing DNA Damage. Mech. Ageing Dev. 2018, 173, 29-38. [CrossRef]

24. Specchia, V.; Bozzetti, M.P. The Role of HSP90 in Preserving the Integrity of Genomes Against Transposons Is Evolutionarily Conserved. Cells 2021, 10, 1096. [CrossRef]

25. Hsu, P.-S.; Yu, S.-H.; Tsai, Y.-T.; Chang, J.-Y.; Tsai, L.-K.; Ye, C.-H.; Song, N.-Y.; Yau, L.-C.; Lin, S.-P. More than Causing (Epi)Genomic Instability: Emerging Physiological Implications of Transposable Element Modulation. J. Biomed. Sci. 2021, 28, 58. [CrossRef]

26. Lerat, E.; Casacuberta, J.; Chaparro, C.; Vieira, C. On the Importance to Acknowledge Transposable Elements in Epigenomic Analyses. Genes 2019, 10, 258. [CrossRef] [PubMed]

27. Lannes, R.; Rizzon, C.; Lerat, E. Does the Presence of Transposable Elements Impact the Epigenetic Environment of Human Duplicated Genes? Genes 2019, 10, 249. [CrossRef]

28. Barrero, M.J. Epigenetic Regulation of the Non-Coding Genome: Opportunities for Immuno-Oncology. Epigenomes 2020, 4, 22. [CrossRef] [PubMed]

29. Grundy, E.E.; Diab, N.; Chiappinelli, K.B. Transposable Element Regulation and Expression in Cancer. FEBS J. 2021 , febs.15722. [CrossRef] [PubMed]

30. Ponomaryova, A.A.; Rykova, E.Y.; Gervas, P.A.; Cherdyntseva, N.V.; Mamedov, I.Z.; Azhikina, T.L. Aberrant Methylation of LINE-1 Transposable Elements: A Search for Cancer Biomarkers. Cells 2020, 9, 2017. [CrossRef]

31. Ferreira, P.G.; Jares, P.; Rico, D.; Gómez-López, G.; Martínez-Trillos, A.; Villamor, N.; Ecker, S.; González-Pérez, A.; Knowles, D.G.; Monlong, J.; et al. Transcriptome Characterization by RNA Sequencing Identifies a Major Molecular and Clinical Subdivision in Chronic Lymphocytic Leukemia. Genome Res. 2014, 24, 212-226. [CrossRef] [PubMed]

32. Tubio, J.M.C.; Li, Y.; Ju, Y.S.; Martincorena, I.; Cooke, S.L.; Tojo, M.; Gundem, G.; Pipinikas, C.P.; Zamora, J.; Raine, K.; et al. Mobile DNA in Cancer. Extensive Transduction of Nonrepetitive DNA Mediated by L1 Retrotransposition in Cancer Genomes. Science 2014, 345, 1251343. [CrossRef] [PubMed]

33. Hedges, D.J.; Deininger, P.L. Inviting Instability: Transposable Elements, Double-Strand Breaks, and the Maintenance of Genome Integrity. Mutat. Res. Fundam. Mol. Mech. Mutagenes. 2007, 616, 46-59. [CrossRef]

34. Wang, C.; Liang, C. The Insertion and Dysregulation of Transposable Elements in Osteosarcoma and Their Association with Patient Event-Free Survival. Sci. Rep. 2022, 12, 377. [CrossRef] [PubMed] 
35. Protasova, M.S.; Andreeva, T.V.; Rogaev, E.I. Factors Regulating the Activity of LINE1 Retrotransposons. Genes 2021, $12,1562$. [CrossRef]

36. Servant, G.; Streva, V.A.; Derbes, R.S.; Wijetunge, M.I.; Neeland, M.; White, T.B.; Belancio, V.P.; Roy-Engel, A.M.; Deininger, P.L. The Nucleotide Excision Repair Pathway Limits L1 Retrotransposition. Genetics 2017, 205, 139-153. [CrossRef] [PubMed]

37. Coufal, N.G.; Garcia-Perez, J.L.; Peng, G.E.; Marchetto, M.C.N.; Muotri, A.R.; Mu, Y.; Carson, C.T.; Macia, A.; Moran, J.V.; Gage, F.H. Ataxia Telangiectasia Mutated (ATM) Modulates Long Interspersed Element-1 (L1) Retrotransposition in Human Neural Stem Cells. Proc. Natl. Acad. Sci. USA 2011, 108, 20382-20387. [CrossRef]

38. Mita, P.; Sun, X.; Fenyö, D.; Kahler, D.J.; Li, D.; Agmon, N.; Wudzinska, A.; Keegan, S.; Bader, J.S.; Yun, C.; et al. BRCA1 and S Phase DNA Repair Pathways Restrict LINE-1 Retrotransposition in Human Cells. Nat. Struct. Mol. Biol. 2020, $27,179-191$. [CrossRef]

39. Brégnard, C.; Guerra, J.; Déjardin, S.; Passalacqua, F.; Benkirane, M.; Laguette, N. Upregulated LINE-1 Activity in the Fanconi Anemia Cancer Susceptibility Syndrome Leads to Spontaneous Pro-Inflammatory Cytokine Production. EBioMedicine 2016, 8 , 184-194. [CrossRef] [PubMed]

40. Ariumi, Y.; Kawano, K.; Yasuda-Inoue, M.; Kuroki, M.; Fukuda, H.; Siddiqui, R.; Turelli, P.; Tateishi, S. DNA Repair Protein Rad18 Restricts LINE-1 Mobility. Sci. Rep. 2018, 8, 15894. [CrossRef]

41. Morales, M.E.; Kaul, T.; Walker, J.; Everett, C.; White, T.; Deininger, P. Altered DNA Repair Creates Novel Alu/Alu Repeatmediated Deletions. Hum. Mutat. 2021, 42, 600-613. [CrossRef]

42. Morales, M.E.; White, T.B.; Streva, V.A.; DeFreece, C.B.; Hedges, D.J.; Deininger, P.L. The Contribution of Alu Elements to Mutagenic DNA Double-Strand Break Repair. PLoS Genet. 2015, 11, e1005016. [CrossRef] [PubMed]

43. Pradhan, R.K.; Ramakrishna, W. Transposons: Unexpected Players in Cancer. Gene 2022, 808, 145975. [CrossRef] [PubMed]

44. Marasca, F.; Gasparotto, E.; Polimeni, B.; Vadalà, R.; Ranzani, V.; Bodega, B. The Sophisticated Transcriptional Response Governed by Transposable Elements in Human Health and Disease. Int. J. Mol. Sci. 2020, 21, 3201. [CrossRef] [PubMed]

45. Burns, K.H. Transposable Elements in Cancer. Nat. Rev. Cancer 2017, 17, 415-424. [CrossRef]

46. Chénais, B. Transposable Elements and Human Cancer: A Causal Relationship? Biochim. Biophys. Acta Rev. Cancer 2013, 1835, 28-35. [CrossRef]

47. Lynch-Sutherland, C.F.; Chatterjee, A.; Stockwell, P.A.; Eccles, M.R.; Macaulay, E.C. Reawakening the Developmental Origins of Cancer Through Transposable Elements. Front. Oncol. 2020, 10, 468. [CrossRef]

48. Shah, A.H.; Gilbert, M.; Ivan, M.E.; Komotar, R.J.; Heiss, J.; Nath, A. The Role of Human Endogenous Retroviruses in Gliomas: From Etiological Perspectives and Therapeutic Implications. Neuro-Oncology 2021, 23, 1647-1655. [CrossRef]

49. Helmprobst, F.; Kneitz, S.; Klotz, B.; Naville, M.; Dechaud, C.; Volff, J.-N.; Schartl, M. Differential Expression of Transposable Elements in the Medaka Melanoma Model. PLoS ONE 2021, 16, e0251713. [CrossRef]

50. Park, M.-K.; Lee, J.-C.; Lee, J.-W.; Hwang, S.-J. Alu Cell-Free DNA Concentration, Alu Index, and LINE-1 Hypomethylation as a Cancer Predictor. Clin. Biochem. 2021, 94, 67-73. [CrossRef]

51. Zhu, X.; Fang, H.; Gladysz, K.; Barbour, J.A.; Wong, J.W.H. Overexpression of Transposable Elements Is Associated with Immune Evasion and Poor Outcome in Colorectal Cancer. Eur. J. Cancer 2021, 157, 94-107. [CrossRef]

52. Lee, E.; Iskow, R.; Yang, L.; Gokcumen, O.; Haseley, P.; Luquette, L.J.; Lohr, J.G.; Harris, C.C.; Ding, L.; Wilson, R.K.; et al. Landscape of Somatic Retrotransposition in Human Cancers. Science 2012, 337, 967-971. [CrossRef] [PubMed]

53. Cajuso, T.; Sulo, P.; Tanskanen, T.; Katainen, R.; Taira, A.; Hänninen, U.A.; Kondelin, J.; Forsström, L.; Välimäki, N.; Aavikko, M.; et al. Retrotransposon Insertions Can Initiate Colorectal Cancer and Are Associated with Poor Survival. Nat. Commun. 2019, 10, 4022. [CrossRef] [PubMed]

54. Morse, B.; Rotherg, P.G.; South, V.J.; Spandorfer, J.M.; Astrin, S.M. Insertional Mutagenesis of the Myc Locus by a LINE-1 Sequence in a Human Breast Carcinoma. Nature 1988, 333, 87-90. [CrossRef] [PubMed]

55. Clayton, E.A.; Wang, L.; Rishishwar, L.; Wang, J.; McDonald, J.F.; Jordan, I.K. Patterns of Transposable Element Expression and Insertion in Cancer. Front. Mol. BioSci. 2016, 3, 76. [CrossRef]

56. Rodriguez-Martin, B.; Alvarez, E.G.; Baez-Ortega, A.; Zamora, J.; Supek, F.; Demeulemeester, J.; Santamarina, M.; Ju, Y.S.; Temes, J.; Garcia-Souto, D.; et al. Pan-Cancer Analysis of Whole Genomes Identifies Driver Rearrangements Promoted by LINE-1 Retrotransposition. Nat. Genet. 2020, 52, 306-319. [CrossRef]

57. Steely, C.J.; Russell, K.L.; Feusier, J.E.; Qiao, Y.; Tavtigian, S.V.; Marth, G.; Jorde, L.B. Mobile Element Insertions and Associated Structural Variants in Longitudinal Breast Cancer Samples. Sci. Rep. 2021, 11, 13020. [CrossRef]

58. Thomas, C.; Oehl-Huber, K.; Bens, S.; Soschinski, P.; Koch, A.; Nemes, K.; Oyen, F.; Kordes, U.; Kool, M.; Frühwald, M.C.; et al. Transposable Element Insertion as a Mechanism of SMARCB1 Inactivation in Atypical Teratoid/Rhabdoid Tumor. Genes Chromosomes Cancer 2021, 60, 586-590. [CrossRef]

59. Mazoyer, S. Genomic Rearrangements in TheBRCA1 AndBRCA2 Genes. Hum. Mutat. 2005, 25, 415-422. [CrossRef]

60. Miki, Y.; Katagiri, T.; Kasumi, F.; Yoshimoto, T.; Nakamura, Y. Mutation Analysis in the BRCA2 Gene in Primary Breast Cancers. Nat. Genet. 1996, 13, 245-247. [CrossRef]

61. Hsieh, S.-Y.; Chen, W.-Y.; Yeh, T.-S.; Sheen, I.-S.; Huang, S.-F. High-Frequency Alu-Mediated Genomic Recombination/Deletion within the Caspase-Activated DNase Gene in Human Hepatoma. Oncogene 2005, 24, 6584-6589. [CrossRef]

62. Oliveira, C.; Senz, J.; Kaurah, P.; Pinheiro, H.; Sanges, R.; Haegert, A.; Corso, G.; Schouten, J.; Fitzgerald, R.; Vogelsang, H.; et al. Germline CDH1 Deletions in Hereditary Diffuse Gastric Cancer Families. Hum. Mol. Genet. 2009, 18, 1545-1555. [CrossRef] 
63. Franke, G.; Bausch, B.; Hoffmann, M.M.; Cybulla, M.; Wilhelm, C.; Kohlhase, J.; Scherer, G.; Neumann, H.P.H. Alu-Alu Recombination Underlies the Vast Majority of Large VHL Germline Deletions: Molecular Characterization and GenotypePhenotype Correlations in VHL Patients. Hum. Mutat. 2009, 30, 776-786. [CrossRef]

64. Strout, M.P.; Marcucci, G.; Bloomfield, C.D.; Caligiuri, M.A. The Partial Tandem Duplication of ALL1 (MLL) Is Consistently Generated by Alu-Mediated Homologous Recombination in Acute Myeloid Leukemia. Proc. Natl. Acad. Sci. USA 1998, 95, 2390-2395. [CrossRef]

65. O’Neil, J.; Tchinda, J.; Gutierrez, A.; Moreau, L.; Maser, R.S.; Wong, K.-K.; Li, W.; McKenna, K.; Liu, X.S.; Feng, B.; et al. Alu Elements Mediate MYB Gene Tandem Duplication in Human T-ALL. J. Exp. Med. 2007, 204, 3059-3066. [CrossRef]

66. Jeffs, A.R.; Benjes, S.M.; Smith, T.L.; Sowerby, S.J.; Morris, C.M. The BCR Gene Recombines Preferentially with Alu Elements in Complex BCR-ABL Translocations of Chronic Myeloid Leukaemia. Hum. Mol. Genet. 1998, 7, 767-776. [CrossRef] [PubMed]

67. Onno, M.; Nakamura, T.; Hillova, J.; Hill, M. Rearrangement of the Human Tre Oncogene by Homologous Recombination between Alu Repeats of Nucleotide Sequences from Two Different Chromosomes. Oncogene 1992, 7, 2519-2523. [PubMed]

68. Curty, G.; Marston, J.L.; de Mulder Rougvie, M.; Leal, F.E.; Nixon, D.F.; Soares, M.A. Human Endogenous Retrovirus K in Cancer: A Potential Biomarker and Immunotherapeutic Target. Viruses 2020, 12, 726. [CrossRef]

69. Grabski, D.F.; Hu, Y.; Sharma, M.; Rasmussen, S.K. Close to the Bedside: A Systematic Review of Endogenous Retroviruses and Their Impact in Oncology. J. Surg. Res. 2019, 240, 145-155. [CrossRef]

70. Barth, M.; Gröger, V.; Cynis, H.; Staege, M.S. Identification of Human Endogenous Retrovirus Transcripts in Hodgkin Lymphoma Cells. Mol. Biol. Rep. 2019, 46, 1885-1893. [CrossRef] [PubMed]

71. Montesion, M.; Williams, Z.H.; Subramanian, R.P.; Kuperwasser, C.; Coffin, J.M. Promoter Expression of HERV-K (HML2) Provirus-Derived Sequences Is Related to LTR Sequence Variation and Polymorphic Transcription Factor Binding Sites. Retrovirology 2018, 15, 57. [CrossRef] [PubMed]

72. Matteucci, C.; Balestrieri, E.; Argaw-Denboba, A.; Sinibaldi-Vallebona, P. Human Endogenous Retroviruses Role in Cancer Cell Stemness. Semin. Cancer Biol. 2018, 53, 17-30. [CrossRef] [PubMed]

73. Babaian, A.; Romanish, M.T.; Gagnier, L.; Kuo, L.Y.; Karimi, M.M.; Steidl, C.; Mager, D.L. Onco-Exaptation of an Endogenous Retroviral LTR Drives IRF5 Expression in Hodgkin Lymphoma. Oncogene 2016, 35, 2542-2546. [CrossRef]

74. Ishak, C.A.; Classon, M.; De Carvalho, D.D. Deregulation of Retroelements as an Emerging Therapeutic Opportunity in Cancer. Trends Cancer 2018, 4, 583-597. [CrossRef]

75. Ross, J.P.; Rand, K.N.; Molloy, P.L. Hypomethylation of Repeated DNA Sequences in Cancer. Epigenomics 2010, 2, 245-269. [CrossRef] [PubMed]

76. Zhao, Y.; Oreskovic, E.; Zhang, Q.; Lu, Q.; Gilman, A.; Lin, Y.S.; He, J.; Zheng, Z.; Lu, J.Y.; Lee, J.; et al. Transposon-Triggered Innate Immune Response Confers Cancer Resistance to the Blind Mole Rat. Nat. Immunol. 2021, 22, 1219-1230. [CrossRef]

77. Akimoto, N.; Zhao, M.; Ugai, T.; Zhong, R.; Lau, M.C.; Fujiyoshi, K.; Kishikawa, J.; Haruki, K.; Arima, K.; Twombly, T.S.; et al Tumor Long Interspersed Nucleotide Element-1 (LINE-1) Hypomethylation in Relation to Age of Colorectal Cancer Diagnosis and Prognosis. Cancers 2021, 13, 2016. [CrossRef]

78. Camuzi, D.; Buexm, L.A.; Lourenço, S.d.Q.C.; Esposti, D.D.; Cuenin, C.; Lopes, M.d.S.A.; Manara, F.; Talukdar, F.R.; Herceg, Z.; Ribeiro Pinto, L.F.; et al. HPV Infection Leaves a DNA Methylation Signature in Oropharyngeal Cancer Affecting Both Coding Genes and Transposable Elements. Cancers 2021, 13, 3621. [CrossRef]

79. Gu, Z.; Liu, Y.; Zhang, Y.; Cao, H.; Lyu, J.; Wang, X.; Wylie, A.; Newkirk, S.J.; Jones, A.E.; Lee, M.; et al. Silencing of LINE-1 Retrotransposons Is a Selective Dependency of Myeloid Leukemia. Nat. Genet. 2021, 53, 672-682. [CrossRef]

80. Scott, E.C.; Gardner, E.J.; Masood, A.; Chuang, N.T.; Vertino, P.M.; Devine, S.E. A Hot L1 Retrotransposon Evades Somatic Repression and Initiates Human Colorectal Cancer. Genome Res. 2016, 26, 745-755. [CrossRef]

81. Groh, S.; Schotta, G. Silencing of Endogenous Retroviruses by Heterochromatin. Cell. Mol. Life Sci. 2017, 74, 2055-2065. [CrossRef]

82. Fukuda, K.; Shinkai, Y. SETDB1-Mediated Silencing of Retroelements. Viruses 2020, 12, 596. [CrossRef]

83. Cuellar, T.L.; Herzner, A.-M.; Zhang, X.; Goyal, Y.; Watanabe, C.; Friedman, B.A.; Janakiraman, V.; Durinck, S.; Stinson, J.; Arnott, D.; et al. Silencing of Retrotransposons by SETDB1 Inhibits the Interferon Response in Acute Myeloid Leukemia. J. Cell Biol. 2017, 216, 3535-3549. [CrossRef]

84. Harteveld, K.L.; Losekoot, M.; Fodde, R.; Giordano, P.C.; Bernini, L.F. The Involvement of Alu Repeats in Recombination Events at the Alpha-Globin Gene Cluster: Characterization of Two Alphazero-Thalassaemia Deletion Breakpoints. Hum. Genet. 1997, 99, 528-534. [CrossRef]

85. Yu, J.; Xie, J.; Luo, L.; Li, Z. An Alu Element-Mediated $28.5 \mathrm{~Kb} \alpha$-Thalassemia Deletion Found in a Chinese Family. Hemoglobin 2014, 38, 427-430. [CrossRef]

86. Henthorn, P.S.; Mager, D.L.; Huisman, T.H.; Smithies, O. A Gene Deletion Ending within a Complex Array of Repeated Sequences $3^{\prime}$ to the Human Beta-Globin Gene Cluster. Proc. Natl. Acad. Sci. USA 1986, 83, 5194-5198. [CrossRef] [PubMed]

87. Phylipsen, M.; Vogelaar, I.P.; Schaap, R.A.C.; Arkesteijn, S.G.J.; Boxma, G.L.; van Helden, W.C.H.; Wildschut, I.C.M.; de Bruin-Roest, A.C.; Giordano, P.C.; Harteveld, C.L. A New Alpha(0)-Thalassemia Deletion Found in a Dutch Family (_AW). Blood Cells Mol. Dis. 2010, 45, 133-135. [CrossRef] [PubMed]

88. Lanikova, L.; Kucerova, J.; Indrak, K.; Divoka, M.; Issa, J.-P.; Papayannopoulou, T.; Prchal, J.T.; Divoky, V. $\beta$-Thalassemia Due to Intronic LINE-1 Insertion in the $\beta$-Globin Gene (HBB): Molecular Mechanisms Underlying Reduced Transcript Levels of the $\beta$-Globin(L1) Allele. Hum. Mutat. 2013, 34, 1361-1365. [CrossRef] [PubMed] 
89. Huang, L.S.; Ripps, M.E.; Korman, S.H.; Deckelbaum, R.J.; Breslow, J.L. Hypobetalipoproteinemia Due to an Apolipoprotein B Gene Exon 21 Deletion Derived by Alu-Alu Recombination. J. Biol. Chem. 1989, 264, 11394-11400. [CrossRef]

90. Hobbs, H.H.; Brown, M.S.; Goldstein, J.L. Molecular Genetics of the LDL Receptor Gene in Familial Hypercholesterolemia. Hum. Mutat. 1992, 1, 445-466. [CrossRef]

91. Jelassi, A.; Slimani, A.; Rabès, J.P.; Jguirim, I.; Abifadel, M.; Boileau, C.; Najah, M.; M'rabet, S.; Mzid, J.; Slimane, M.N.; et al. Genomic Characterization of Two Deletions in the LDLR Gene in Tunisian Patients with Familial Hypercholesterolemia. Clin. Chim. Acta 2012, 414, 146-151. [CrossRef]

92. Miné, M.; Chen, J.-M.; Brivet, M.; Desguerre, I.; Marchant, D.; de Lonlay, P.; Bernard, A.; Férec, C.; Abitbol, M.; Ricquier, D.; et al. A Large Genomic Deletion in the PDHX Gene Caused by the Retrotranspositional Insertion of a Full-Length LINE-1 Element. Hum. Mutat. 2007, 28, 137-142. [CrossRef]

93. Mitchell, G.A.; Labuda, D.; Fontaine, G.; Saudubray, J.M.; Bonnefont, J.P.; Lyonnet, S.; Brody, L.C.; Steel, G.; Obie, C.; Valle, D Splice-Mediated Insertion of an Alu Sequence Inactivates Ornithine Delta-Aminotransferase: A Role for Alu Elements in Human Mutation. Proc. Natl. Acad. Sci. USA 1991, 88, 815-819. [CrossRef] [PubMed]

94. Vervoort, R.; Gitzelmann, R.; Lissens, W.; Liebaers, I. A Mutation (IVS8+0.6kbdelTC) Creating a New Donor Splice Site Activates a Cryptic Exon in an Alu-Element in Intron 8 of the Human Beta-Glucuronidase Gene. Hum. Genet. 1998, 103, 686-693. [CrossRef] [PubMed]

95. Meischl, C.; Boer, M.; Ahlin, A.; Roos, D. A New Exon Created by Intronic Insertion of a Rearranged LINE-1 Element as the Cause of Chronic Granulomatous Disease. Eur. J. Hum. Genet. 2000, 8, 697-703. [CrossRef]

96. Ahmadi, A.; De Toma, I.; Vilor-Tejedor, N.; Eftekhariyan Ghamsari, M.R.; Sadeghi, I. Transposable Elements in Brain Health and Disease. Ageing Res. Rev. 2020, 64, 101153. [CrossRef]

97. Martínez-Garay, I.; Ballesta, M.J.; Oltra, S.; Orellana, C.; Palomeque, A.; Moltó, M.D.; Prieto, F.; Martínez, F. Intronic L1 Insertion and F268S, Novel Mutations in RPS6KA3 (RSK2) Causing Coffin-Lowry Syndrome. Clin. Genet. 2003, 64, 491-496. [CrossRef] [PubMed]

98. Kornreich, R.; Bishop, D.F.; Desnick, R.J. Alpha-Galactosidase A Gene Rearrangements Causing Fabry Disease. Identification of Short Direct Repeats at Breakpoints in an Alu-Rich Gene. J. Biol. Chem. 1990, 265, 9319-9326. [CrossRef]

99. Shabbeer, J.; Yasuda, M.; Benson, S.D.; Desnick, R.J. Fabry Disease: Identification of 50 Novel Alpha-Galactosidase A Mutations Causing the Classic Phenotype and Three-Dimensional Structural Analysis of 29 Missense Mutations. Hum. Genom. 2006, 2, 297-309. [CrossRef]

100. Neote, K.; McInnes, B.; Mahuran, D.J.; Gravel, R.A. Structure and Distribution of an Alu-Type Deletion Mutation in Sandhoff Disease. J. Clin. Investig. 1990, 86, 1524-1531. [CrossRef]

101. Wallace, M.R.; Andersen, L.B.; Saulino, A.M.; Gregory, P.E.; Glover, T.W.; Collins, F.S. A de Novo Alu Insertion Results in Neurofibromatosis Type 1. Nature 1991, 353, 864-866. [CrossRef]

102. Li, W.; Jin, Y.; Prazak, L.; Hammell, M.; Dubnau, J. Transposable Elements in TDP-43-Mediated Neurodegenerative Disorders PLOS ONE 2012, 7, e44099. [CrossRef]

103. Petrozziello, T.; Dios, A.M.; Mueller, K.A.; Vaine, C.A.; Hendriks, W.T.; Glajch, K.E.; Mills, A.N.; Mangkalaphiban, K.; Penney, E.B.; Ito, N.; et al. SVA Insertion in X-Linked Dystonia Parkinsonism Alters Histone H3 Acetylation Associated with TAF1 Gene. PLoS ONE 2020, 15, e0243655. [CrossRef] [PubMed]

104. Sankowski, R.; Strohl, J.J.; Huerta, T.S.; Nasiri, E.; Mazzarello, A.N.; D’Abramo, C.; Cheng, K.F.; Staszewski, O.; Prinz, M.; Huerta, P.T.; et al. Endogenous Retroviruses Are Associated with Hippocampus-Based Memory Impairment. Proc. Natl. Acad. Sci. USA 2019, 116, 25982-25990. [CrossRef] [PubMed]

105. Guffanti, G.; Gaudi, S.; Fallon, J.H.; Sobell, J.; Potkin, S.G.; Pato, C.; Macciardi, F. Transposable Elements and Psychiatric Disorders. Am. J. Med. Genet. B Neuropsychiatr. Genet. 2014, 165B, 201-216. [CrossRef]

106. Misiak, B.; Ricceri, L.; Sąsiadek, M.M. Transposable Elements and Their Epigenetic Regulation in Mental Disorders: Current Evidence in the Field. Front. Genet. 2019, 10, 580. [CrossRef]

107. Lapp, H.E.; Hunter, R.G. Early Life Exposures, Neurodevelopmental Disorders, and Transposable Elements. Neurobiol. Stress 2019, 11, 100174. [CrossRef]

108. Li, S.; Yang, Q.; Hou, Y.; Jiang, T.; Zong, L.; Wang, Z.; Luo, X.; Liang, W.; Zhao, H.; Ning, Y.; et al. Hypomethylation of LINE-1 Elements in Schizophrenia and Bipolar Disorder. J. Psychiatr. Res. 2018, 107, 68-72. [CrossRef]

109. Doyle, G.A.; Crist, R.C.; Karatas, E.T.; Hammond, M.J.; Ewing, A.D.; Ferraro, T.N.; Hahn, C.-G.; Berrettini, W.H. Analysis of LINE-1 Elements in DNA from Postmortem Brains of Individuals with Schizophrenia. Neuropsychopharmacology 2017, 42, 2602-2611. [CrossRef] [PubMed]

110. Schneider, I.; Kugel, H.; Redlich, R.; Grotegerd, D.; Bürger, C.; Bürkner, P.-C.; Opel, N.; Dohm, K.; Zaremba, D.; Meinert, S.; et al. Association of Serotonin Transporter Gene AluJb Methylation with Major Depression, Amygdala Responsiveness, 5-HTTLPR/Rs25531 Polymorphism, and Stress. Neuropsychopharmacology 2018, 43, 1308-1316. [CrossRef]

111. Lapp, H.E.; Ahmed, S.; Moore, C.L.; Hunter, R.G. Toxic Stress History and Hypothalamic-Pituitary-Adrenal Axis Function in a Social Stress Task: Genetic and Epigenetic Factors. Neurotoxicol. Teratol. 2019, 71, 41-49. [CrossRef]

112. Shpyleva, S.; Melnyk, S.; Pavliv, O.; Pogribny, I.; Jill James, S. Overexpression of LINE-1 Retrotransposons in Autism Brain. Mol. NeuroBiol. 2018, 55, 1740-1749. [CrossRef] 
113. Tangsuwansri, C.; Saeliw, T.; Thongkorn, S.; Chonchaiya, W.; Suphapeetiporn, K.; Mutirangura, A.; Tencomnao, T.; Hu, V.W.; Sarachana, T. Investigation of Epigenetic Regulatory Networks Associated with Autism Spectrum Disorder (ASD) by Integrated Global LINE-1 Methylation and Gene Expression Profiling Analyses. PLoS ONE 2018, 13, e0201071. [CrossRef]

114. Saeliw, T.; Tangsuwansri, C.; Thongkorn, S.; Chonchaiya, W.; Suphapeetiporn, K.; Mutirangura, A.; Tencomnao, T.; Hu, V.W.; Sarachana, T. Integrated Genome-Wide Alu Methylation and Transcriptome Profiling Analyses Reveal Novel Epigenetic Regulatory Networks Associated with Autism Spectrum Disorder. Mol. Autism 2018, 9, 27. [CrossRef]

115. Canli, T. A Model of Human Endogenous Retrovirus (HERV) Activation in Mental Health and Illness. Med. Hypotheses 2019, 133, 109404. [CrossRef] [PubMed]

116. Szafranski, P.; Liu, Q.; Karolak, J.A.; Song, X.; de Leeuw, N.; Faas, B.; Gerychova, R.; Janku, P.; Jezova, M.; Valaskova, I.; et al. Association of Rare Non-Coding SNVs in the Lung-Specific FOXF1 Enhancer with a Mitigation of the Lethal ACDMPV Phenotype. Hum. Genet. 2019, 138, 1301-1311. [CrossRef]

117. Ganguly, A.; Dunbar, T.; Chen, P.; Godmilow, L.; Ganguly, T. Exon Skipping Caused by an Intronic Insertion of a Young Alu Yb9 Element Leads to Severe Hemophilia A. Hum. Genet. 2003, 113, 348-352. [CrossRef]

118. Oldridge, M.; Zackai, E.H.; McDonald-McGinn, D.M.; Iseki, S.; Morriss-Kay, G.M.; Twigg, S.R.; Johnson, D.; Wall, S.A.; Jiang, W.; Theda, C.; et al. De Novo Alu-Element Insertions in FGFR2 Identify a Distinct Pathological Basis for Apert Syndrome. Am. J. Hum. Genet. 1999, 64, 446-461. [CrossRef]

119. Knebelmann, B.; Forestier, L.; Drouot, L.; Quinones, S.; Chuet, C.; Benessy, F.; Saus, J.; Antignac, C. Splice-Mediated Insertion of an Alu Sequence in the COL4A3 MRNA Causing Autosomal Recessive Alport Syndrome. Hum. Mol. Genet. 1995, 4, 675-679. [CrossRef] [PubMed]

120. Narita, N.; Nishio, H.; Kitoh, Y.; Ishikawa, Y.; Ishikawa, Y.; Minami, R.; Nakamura, H.; Matsuo, M. Insertion of a $5^{\prime}$ Truncated L1 Element into the $3^{\prime}$ End of Exon 44 of the Dystrophin Gene Resulted in Skipping of the Exon during Splicing in a Case of Duchenne Muscular Dystrophy. J. Clin. Investig. 1993, 91, 1862-1867. [CrossRef] [PubMed]

121. Ferlini, A.; Galié, N.; Merlini, L.; Sewry, C.; Branzi, A.; Muntoni, F. A Novel Alu-like Element Rearranged in the Dystrophin Gene Causes a Splicing Mutation in a Family with X-Linked Dilated Cardiomyopathy. Am. J. Hum. Genet. 1998, 63, 436-446. [CrossRef]

122. Gallus, G.N.; Cardaioli, E.; Rufa, A.; Da Pozzo, P.; Bianchi, S.; D’Eramo, C.; Collura, M.; Tumino, M.; Pavone, L.; Federico, A. Alu-Element Insertion in an OPA1 Intron Sequence Associated with Autosomal Dominant Optic Atrophy. Mol. Vis. 2010, 16, 178-183.

123. Kondo-Iida, E.; Kobayashi, K.; Watanabe, M.; Sasaki, J.; Kumagai, T.; Koide, H.; Saito, K.; Osawa, M.; Nakamura, Y.; Toda, T. Novel Mutations and Genotype-Phenotype Relationships in 107 Families with Fukuyama-Type Congenital Muscular Dystrophy (FCMD). Hum. Mol. Genet. 1999, 8, 2303-2309. [CrossRef] [PubMed]

124. Ricci, V.; Regis, S.; Di Duca, M.; Filocamo, M. An Alu-Mediated Rearrangement as Cause of Exon Skipping in Hunter Disease. Hum. Genet. 2003, 112, 419-425. [CrossRef] [PubMed]

125. Schwahn, U.; Lenzner, S.; Dong, J.; Feil, S.; Hinzmann, B.; van Duijnhoven, G.; Kirschner, R.; Hemberger, M.; Bergen, A.A.B.; Rosenberg, T.; et al. Positional Cloning of the Gene for X-Linked Retinitis Pigmentosa 2. Nat. Genet. 1998, 19, 327-332. [CrossRef]

126. Vidaud, D.; Vidaud, M.; Bahnak, B.R.; Siguret, V.; Gispert Sanchez, S.; Laurian, Y.; Meyer, D.; Goossens, M.; Lavergne, J.M. Haemophilia B Due to a De Novo Insertion of a Human-Specific Alu Subfamily Member within the Coding Region of the Factor IX Gene. Eur. J. Hum. Genet. 1993, 1, 30-36. [CrossRef] [PubMed]

127. Tighe, P.J.; Stevens, S.E.; Dempsey, S.; Le Deist, F.; Rieux-Laucat, F.; Edgar, J.D.M. Inactivation of the Fas Gene by Alu Insertion: Retrotransposition in an Intron Causing Splicing Variation and Autoimmune Lymphoproliferative Syndrome. Genes Immun. 2002, 3, S66-S70. [CrossRef]

128. Janicic, N.; Pausova, Z.; Cole, D.E.; Hendy, G.N. Insertion of an Alu Sequence in the $\mathrm{Ca}^{2+}{ }_{-}$Sensing Receptor Gene in Familial Hypocalciuric Hypercalcemia and Neonatal Severe Hyperparathyroidism. Am. J. Hum. Genet. 1995, 56, 880-886.

129. Rostami, M.R.; Bradic, M. The Derepression of Transposable Elements in Lung Cells Is Associated with the Inflammatory Response and Gene Activation in Idiopathic Pulmonary Fibrosis. Mob. DNA 2021, 12, 14. [CrossRef]

130. Helmy, M.; Selvarajoo, K. Systems Biology to Understand and Regulate Human Retroviral Proinflammatory Response. Front. Immunol. 2021, 12, 736349. [CrossRef] [PubMed]

131. Bergallo, M.; Galliano, I.; Montanari, P.; Zaniol, E.; Graziano, E.; Calvi, C.; Alliaudi, C.; Daprà, V.; Savino, F. Modulation of Human Endogenous Retroviruses -H, -W and -K Transcription by Microbes. Microbes Infect. 2020, 22, 366-370. [CrossRef]

132. Lima-Junior, D.S.; Krishnamurthy, S.R.; Bouladoux, N.; Collins, N.; Han, S.-J.; Chen, E.Y.; Constantinides, M.G.; Link, V.M.; Lim, A.I.; Enamorado, M.; et al. Endogenous Retroviruses Promote Homeostatic and Inflammatory Responses to the Microbiota. Cell 2021, 184, 3794-3811.e19. [CrossRef]

133. Payer, L.M.; Steranka, J.P.; Ardeljan, D.; Walker, J.; Fitzgerald, K.C.; Calabresi, P.A.; Cooper, T.A.; Burns, K.H. Alu Insertion Variants Alter MRNA Splicing. Nucleic Acids Res. 2019, 47, 421-431. [CrossRef]

134. Payer, L.M.; Steranka, J.P.; Yang, W.R.; Kryatova, M.; Medabalimi, S.; Ardeljan, D.; Liu, C.; Boeke, J.D.; Avramopoulos, D.; Burns, K.H. Structural Variants Caused by Alu Insertions Are Associated with Risks for Many Human Diseases. Proc. Natl. Acad. Sci. USA 2017, 114, E3984-E3992. [CrossRef]

135. Ramirez, P.; Zuniga, G.; Sun, W.; Beckmann, A.; Ochoa, E.; DeVos, S.L.; Hyman, B.; Chiu, G.; Roy, E.R.; Cao, W.; et al. Pathogenic Tau Accelerates Aging-Associated Activation of Transposable Elements in the Mouse Central Nervous System. Prog. Neurobiol. 2022, 208, 102181. [CrossRef] [PubMed] 
136. Van Meter, M.; Kashyap, M.; Rezazadeh, S.; Geneva, A.J.; Morello, T.D.; Seluanov, A.; Gorbunova, V. SIRT6 Represses LINE1 Retrotransposons by Ribosylating KAP1 but This Repression Fails with Stress and Age. Nat. Commun. 2014, 5, 5011. [CrossRef] [PubMed]

137. Thomas, E.O.; Ramirez, P.; Hyman, B.T.; Ray, W.J.; Frost, B. Testing the Neuroinflammatory Role of Tau-induced Transposable Elements in Tauopathy. Alzheimer's Dement. 2021, 17, e058664. [CrossRef]

138. Guo, C.; Jeong, H.-H.; Hsieh, Y.-C.; Klein, H.-U.; Bennett, D.A.; De Jager, P.L.; Liu, Z.; Shulman, J.M. Tau Activates Transposable Elements in Alzheimer's Disease. Cell Rep. 2018, 23, 2874-2880. [CrossRef] [PubMed]

139. Sun, W.; Samimi, H.; Gamez, M.; Zare, H.; Frost, B. Pathogenic Tau-Induced PiRNA Depletion Promotes Neuronal Death through Transposable Element Dysregulation in Neurodegenerative Tauopathies. Nat. NeuroSci. 2018, 21, 1038-1048. [CrossRef]

140. Lanciano, S.; Mirouze, M. Transposable Elements: All Mobile, All Different, Some Stress Responsive, Some Adaptive? Curr. Opin. Genet. Dev. 2018, 49, 106-114. [CrossRef] [PubMed]

141. Pappalardo, A.M.; Ferrito, V.; Biscotti, M.A.; Canapa, A.; Capriglione, T. Transposable Elements and Stress in Vertebrates: An Overview. Int. J. Mol. Sci. 2021, 22, 1970. [CrossRef]

142. Hou, J.; Lu, D.; Mason, A.S.; Li, B.; Xiao, M.; An, S.; Fu, D. Non-Coding RNAs and Transposable Elements in Plant Genomes: Emergence, Regulatory Mechanisms and Roles in Plant Development and Stress Responses. Planta 2019, 250, 23-40. [CrossRef] [PubMed]

143. Fambrini, M.; Usai, G.; Vangelisti, A.; Mascagni, F.; Pugliesi, C. The Plastic Genome: The Impact of Transposable Elements on Gene Functionality and Genomic Structural Variations. Genesis 2020, 58, e23399. [CrossRef] [PubMed]

144. Baduel, P.; Quadrana, L. Jumpstarting Evolution: How Transposition Can Facilitate Adaptation to Rapid Environmental Changes. Curr. Opin. Plant. Biol. 2021, 61, 102043. [CrossRef] [PubMed]

145. Ramakrishnan, M.; Satish, L.; Kalendar, R.; Narayanan, M.; Kandasamy, S.; Sharma, A.; Emamverdian, A.; Wei, Q.; Zhou, M. The Dynamism of Transposon Methylation for Plant Development and Stress Adaptation. Int. J. Mol. Sci. 2021, 22, 11387. [CrossRef]

146. García Guerreiro, M.P. What Makes Transposable Elements Move in the Drosophila Genome? Heredity 2012, 108, 461-468. [CrossRef]

147. Le Goff, G.; Hilliou, F. Resistance Evolution in Drosophila: The Case of CYP6G1: CYP6G1 in Insecticide Resistance. Pest. Manag. Sci. 2017, 73, 493-499. [CrossRef]

148. Klai, K.; Chénais, B.; Zidi, M.; Djebbi, S.; Caruso, A.; Denis, F.; Confais, J.; Badawi, M.; Casse, N.; Mezghani Khemakhem, M Screening of Helicoverpa Armigera Mobilome Revealed Transposable Element Insertions in Insecticide Resistance Genes. Insects 2020, 11, 879. [CrossRef]

149. Zidi, M.; Denis, F.; Klai, K.; Chénais, B.; Caruso, A.; Djebbi, S.; Mezghani, M.; Casse, N. Genome-Wide Characterization of Mariner-like Transposons and Their Derived MITEs in the Whitefly Bemisia Tabaci (Hemiptera: Aleyrodidae). G3 Genes Genomes Genet. 2021, 11, jkab287. [CrossRef]

150. Del Re, B.; Giorgi, G. Long INterspersed Element-1 Mobility as a Sensor of Environmental Stresses. Environ. Mol. Mutagen. 2020, 61, 465-493. [CrossRef] [PubMed]

151. Shutoh, Y.; Takeda, M.; Ohtsuka, R.; Haishima, A.; Yamaguchi, S.; Fujie, H.; Komatsu, Y.; Maita, K.; Harada, T. Low Dose Effects of Dichlorodiphenyltrichloroethane (DDT) on Gene Transcription and DNA Methylation in the Hypothalamus of Young Male Rats: Implication of Hormesis-like Effects. J. Toxicol. Sci. 2009, 34, 469-482. [CrossRef] [PubMed]

152. Stouder, C.; Paoloni-Giacobino, A. Specific Transgenerational Imprinting Effects of the Endocrine Disruptor Methoxychlor on Male Gametes. Reproduction 2011, 141, 207-216. [CrossRef]

153. Stenz, L.; Rahban, R.; Prados, J.; Nef, S.; Paoloni-Giacobino, A. Genetic Resistance to DEHP-Induced Transgenerational Endocrine Disruption. PLoS ONE 2019, 14, e0208371. [CrossRef]

154. Stenz, L.; Escoffier, J.; Rahban, R.; Nef, S.; Paoloni-Giacobino, A. Testicular Dysgenesis Syndrome and Long-Lasting Epigenetic Silencing of Mouse Sperm Genes Involved in the Reproductive System after Prenatal Exposure to DEHP. PLoS ONE 2017, 12, e0170441. [CrossRef]

155. Kim, K.-Y.; Kim, D.-S.; Lee, S.-K.; Lee, I.-K.; Kang, J.-H.; Chang, Y.-S.; Jacobs, D.R.; Steffes, M.; Lee, D.-H. Association of Low-Dose Exposure to Persistent Organic Pollutants with Global DNA Hypomethylation in Healthy Koreans. Environ. Health Perspect. 2010, 118, 370-374. [CrossRef]

156. Rusiecki, J.A.; Baccarelli, A.; Bollati, V.; Tarantini, L.; Moore, L.E.; Bonefeld-Jorgensen, E.C. Global DNA Hypomethylation Is Associated with High Serum-Persistent Organic Pollutants in Greenlandic Inuit. Environ. Health Perspect 2008, 116, 1547-1552. [CrossRef]

157. Kim, S.; Cho, Y.H.; Lee, I.; Kim, W.; Won, S.; Ku, J.-L.; Moon, H.-B.; Park, J.; Kim, S.; Choi, G.; et al. Prenatal Exposure to Persistent Organic Pollutants and Methylation of LINE-1 and Imprinted Genes in Placenta: A CHECK Cohort Study. Environ. Int. 2018, 119, 398-406. [CrossRef]

158. Lee, M.H.; Cho, E.R.; Lim, J.; Jee, S.H. Association between Serum Persistent Organic Pollutants and DNA Methylation in Korean Adults. Environ. Res. 2017, 158, 333-341. [CrossRef] [PubMed]

159. Alexander, M.; Koutros, S.; Bonner, M.R.; Barry, K.H.; Alavanja, M.C.R.; Andreotti, G.; Byun, H.-M.; Chen, L.; Beane Freeman, L.E.; Hofmann, J.N.; et al. Pesticide Use and LINE-1 Methylation among Male Private Pesticide Applicators in the Agricultural Health Study. Environ. Epigenet. 2017, 3, dvx005. [CrossRef] 
160. Saad-Hussein, A.; Taha, M.M. Epigenetic Study of Global Gene Methylation in PON1, XRCC1 and GSTs Different Genotypes in Rural and Urban Pesticide Exposed Workers. J. Complement. Integr. Med. 2020, 17, 20190166. [CrossRef] [PubMed]

161. Paul, S.; Bhattacharjee, P.; Giri, A.K.; Bhattacharjee, P. Arsenic Toxicity and Epimutagenecity: The New LINEage. Biometals 2017, 30, 505-515. [CrossRef]

162. Collotta, M.; Bertazzi, P.A.; Bollati, V. Epigenetics and Pesticides. Toxicology 2013, 307, 35-41. [CrossRef]

163. Mostafalou, S.; Abdollahi, M. Pesticides and Human Chronic Diseases: Evidences, Mechanisms, and Perspectives. Toxicol. Appl. Pharm. 2013, 268, 157-177. [CrossRef] [PubMed]

164. Legoff, L.; D’Cruz, S.C.; Bouchekhchoukha, K.; Monfort, C.; Jaulin, C.; Multigner, L.; Smagulova, F. In Utero Exposure to Chlordecone Affects Histone Modifications and Activates LINE-1 in Cord Blood. Life Sci. Alliance 2021, 4, e202000944. [CrossRef]

165. Miret, N.; Zappia, C.D.; Altamirano, G.; Pontillo, C.; Zárate, L.; Gómez, A.; Lasagna, M.; Cocca, C.; Kass, L.; Monczor, F.; et al. AhR Ligands Reactivate LINE-1 Retrotransposon in Triple-Negative Breast Cancer Cells MDA-MB-231 and Non-Tumorigenic Mammary Epithelial Cells NMuMG. Biochem. Pharmacol. 2020, 175, 113904. [CrossRef] [PubMed]

166. Karimi, A.; Madjd, Z.; Habibi, L.; Akrami, S.M. Evaluating the Extent of LINE-1 Mobility Following Exposure to Heavy Metals in HepG2 Cells. Biol. Trace Elem. Res. 2014, 160, 143-151. [CrossRef] [PubMed]

167. Tang, Z.; Steranka, J.P.; Ma, S.; Grivainis, M.; Rodić, N.; Huang, C.R.L.; Shih, I.-M.; Wang, T.-L.; Boeke, J.D.; Fenyö, D.; et al. Human Transposon Insertion Profiling: Analysis, Visualization and Identification of Somatic LINE-1 Insertions in Ovarian Cancer. Proc. Natl. Acad. Sci. USA 2017, 114, E733-E740. [CrossRef] [PubMed]

168. Sakamoto, Y.; Zaha, S.; Suzuki, Y.; Seki, M.; Suzuki, A. Application of Long-Read Sequencing to the Detection of Structural Variants in Human Cancer Genomes. Comput. Struct. Biotechnol. J. 2021, 19, 4207-4216. [CrossRef]

169. Chu, C.; Borges-Monroy, R.; Viswanadham, V.V.; Lee, S.; Li, H.; Lee, E.A.; Park, P.J. Comprehensive Identification of Transposable Element Insertions Using Multiple Sequencing Technologies. Nat. Commun. 2021, 12, 3836. [CrossRef] 